Alma Mater Studiorum - Università di Bologna DEPARTMENT OF ECONOMICS

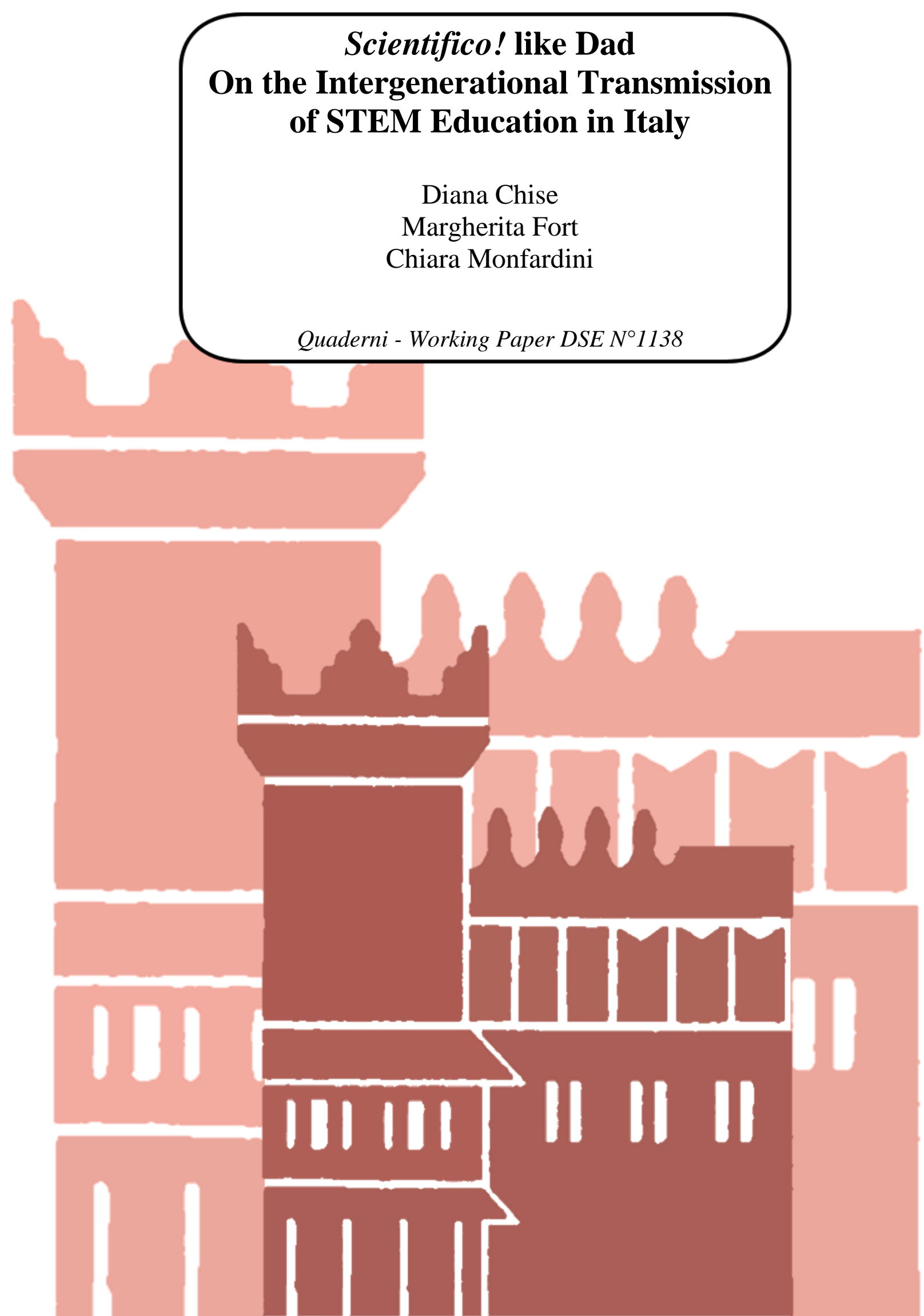




\title{
Scientifico! like Dad On the Intergenerational Transmission of STEM Education in Italy*
}

\author{
Diana Chise Margherita Fort $^{\ddagger} \quad$ Chiara Monfardini ${ }^{\S}$
}

This version: October 11, 2019

\begin{abstract}
We provide novel evidence on the existence and the extent of intergenerational transmission of STEM (Science, Technology, Engineering and Mathematics) education using a recent large administrative dataset of Italian graduates obtained from the Almalaurea data. Parental influence on two STEM educational outcomes (high school and university degree completion) is strong and, net of student's time-invariant unobserved heterogeneity, proves to be stronger at the stage of the educational career closer to labour market entry. At this stage, the influence of fathers outweighs the one of mothers and is larger for sons than for daughters. The documented STEM intergenerational transmission is not driven by liberal profession of parents for most of STEM fields, while it is for some non-STEM fields (economic and legal studies), consistently with the presence of entry barriers in some professions.
\end{abstract}

JEL-Codes: J16, J24, I24

Keywords: gender, intergenerational transmission, parents, STEM

\footnotetext{
${ }^{*}$ This paper borrows from the LMEC master thesis at the University of Bologna of D. Chise, under the supervision of C. Monfardini, entitled "Intergenerational transmission of STEM educational choices in Italy: a gender perspective" (October 2017). "Scientifico!" it is also the title of a performance by A. Libertini and V. Nah (company: Piccoli Prinicipi-Italy/ Athènor -France/ Teatro all'improvviso-Italy), who bring on stage a special science lesson for young children. We are very grateful to D. Cristofori and S. Ghiselli for their help in clarifying the many institutional and administrative details of the AlmaLaurea dataset. Chiara Monfardini gratefully acknowledges financial support of University of Bologna Grant "Ricerca Fondamentale Orientata" (RFO). We acknowledge the outstanding work of P.N. Barro and F. Meluzzi as research assistants. Finally, we are grateful to M. Anelli, E. Cantoni, M. De Paola, G. Moroni, J. Snyder and seminar participants at the Ninth International Workshop on Applied Economics of Education (IX IWAEE), the 17th Brucchi Luchino Labor Economics Workshop in 2018, the 2018 AIEL Conference, the Eighth Italian Congress of Econometrics and Empirical Economics in 2019, the University of Bologna, the University of York and the JRC ISPRA for very valuable comments and suggestions. Authors' email addresses: diana.chise@studio.unibo.it; margherita.fort@unibo.it; chiara.monfardini@unibo.it (corresponding author).

${ }^{\S}$ University of Bologna, Department of Economics, and IZA. Fort is also affiliated with CESifo and FBK-IRVAPP. Monfardini is also affiliated with CHILD-CCA.

${ }^{\ddagger}$ European Central Bank, Directorate General Information Systems.
} 


\section{Non - Technical Summary}

The demand for professional and associate professional occupations in the fields of Science, Technlogy, Engineering and Mathematics (STEM) is expected to grow by $13 \%$ and $7 \%$ respectively in the period 2015-2025 in Europe, as opposed to a predicted 3\% increase in employment for all occupations. In the US, the projected growth of STEM occupations is even more rapid, with the mathematical science occupations group being expected to grow by $28 \%$ over the 2014-2024 period, compared with the $6.5 \%$ predicted growth for all occupations. However, the future supply of STEM related skills is feared to result insufficient worldwide. The ability to attract future generations of STEM students, to stimulate the supply of STEM professionals and to reduce its gender unbalance rests on the understanding of the forces that drive self-selection into STEM fields.

Despite family background is widely recognized as a major determinant of educational attainment in developed countries, the role of parents's education in shaping STEM field choices and graduation of their children has been under-explored so far. The vaste literature on the intergenerational transmission of inequality in education has thouroghly investigated the vertical transmission of years of schooling, emphasizing the importance of allowing for heterogeneous effects according to parents' and children's gender.

In this paper, we use a recent high quality dataset on a large portion of the population of Italian graduates (Almalaurea dataset, 2017 cohort) to provide novel and up-to-date evidence on the existence and the extent of intergenerational transmission of STEM educational outcomes, estimating gendered intergenerational associations according to both parents' and students' gender. We document sizeable intergenerational dependence in STEM (and nonSTEM) field of study. While fathers' influence proves to be stronger than the influence of mothers at university, this is not true at high school. At high school, each parent is similarly important for his/her daughter, but at university fathers are more important for their sons than for their daughters. Evidence provided in the paper clearly indicates that STEM field transmission is not driven by liberal professional parents, while in economic and legal studies field trasmission is largely drive by liberal professional parents.

This research indicates that parental influence is likely to be an important mediator of impact of interventions that aim at promoting STEM fields targetting middle school and high schools students. Based on our results, we can argue that, while - at least in our sample $-43 \%$ of the students makes the same non-STEM field choice at both high school and university, targetting only middle school students may not be fully effective to promote STEM field completion among females at high school (and at University): at early stages of their educational carreer, students are more sensitive to parental role models and this might attenutate program effects. The question of whether targetting simultaneously also parents, who are potentially less-malleable but, at the same time, not always fully informed and aware of their influence, would improve program effectiveness, is open for further research. It would also be interesting to explore whether programs who promote STEM fields targetting students directly induce the unintended effect of significantly reducing intergenerational transmission of field choice. 


\section{Introduction}

The demand for professional and associate professional occupations in the fields of Science, Technlogy, Engineering and Mathematics (STEM) is expected to grow by $13 \%$ and $7 \%$ respectively in the period 2015-2025 in Europe, as opposed to a predicted $3 \%$ increase in employment for all occupations (EU Skills Panorama 2014, 2015). In the US, the projected growth of STEM occupations is even more rapid, with the mathematical science occupations group being expected to grow by $28 \%$ over the $2014-2024$ period, compared with the $6.5 \%$ predicted growth for all occupations (Fayer et al., 2015). However, the future supply of STEM related skills is feared to result insufficient worldwide. This shortage of supply is partly due to the under-representation of women in these fields, which is a reason of growing concern for policymakers and social scientists (European Commission, 2015; UNESCO, 2017; Kahan and Ginther, 2017) and is likely to have implications on the gender gap in wages, since STEM occupations are recognized to be more rewarded in the job market than non-STEM ones (Goos et al., 2013; Fayer et al., 2015). ${ }^{1}$

Recent studies have empirically explored the role of STEM education as a driver of economic performance at the aggregate level. According to Ray (2015), the presence of STEM graduates stimulated economic growth and innovation in the USA, and there is evidence that STEM graduates generate positive externalities on the society at large, improving the earning conditions also of the lower educated (Winters, 2018).

The ability to attract future generations of STEM students, to stimulate the supply of STEM professionals and to reduce its gender unbalance rests on the understanding of the forces that drive self-selection into STEM fields. This has very recently motivated a growing literature exploring the determinants of STEM university entry and completion, as well as their gender gaps, we briefly review in Section 2.

Despite family background is widely recognized as a major determinant of educational attainment in developed countries, the role of parents's education in shaping STEM field choices and graduation of their children has been under-explored so far. The vaste literature on the intergenerational transmission of inequality in education has thouroghly investigated

\footnotetext{
${ }^{1}$ According to this report the national average wage for all STEM occupations in 2015 was nearly double the national average wage for non-STEM occupations in the US.
} 
the vertical transmission of years of schooling (see Björklund and Salvanes (2010); Black and Devereux (2011); Holmlund et al. (2011) for exhaustive reviews), emphasizing the importance of allowing for heterogeneous effects according to parents' and children's gender (Amin et al., 2015). However, to the best of our knowledge, no study so far has addressed explicitely the issue of linking the STEM educational attainments of parents and children, despite the educational expansion over past years increased the importance of horizontal differentiation between fields of study on the one side (Triventi, 2013) and parents have been proved to exert their influence on students' college choice on the other side (Huntington-Klein, 2018).

In this paper, we use a recent high quality dataset on a large portion of the population of Italian graduates (Almalaurea dataset, 2017 cohort) to provide novel and up-to-date evidence on the existence and the extent of intergenerational transmission of STEM educational outcomes, estimating gendered intergenerational associations according to both parents' and students' gender. To this aim, we had access to text-type uncoded information contained in the Almalaurea dataset and identified with an own-built procedure the field of study of the parents.

The case study of Italy we analyse is particularly interesting since the Italian society is characterized by high levels of both intergenerational persistence of educational attainment (Checchi et al., 2013) and gender inequality in the economic participation and opportunity domain (World Economic Forum, 2018). Since the beginning of the nineties, when Italian female graduates have reached their males counterpart, female enrollment has witnessed a continuous increase and stabilized around $60 \%$ of the total number of graduates in the recent years. Despite representing more than half of the graduate population, however, women tend to earn lower wages with respect to men. Piazzalunga (2018) reports an overall gender gap estimated by EUROSTAT (2017) of about 44\%. One of the explanation of this disadvantage can be found in females' under-representation in STEM education, as argued by Anelli and Peri (2015). Indeed, in our sample approximately $23 \%$ of students graduate in STEM fields but this share decreases to $15 \%$ among females, while it is about $34 \%$ among males. $^{2}$

\footnotetext{
${ }^{2}$ According to recent surveys on the Italian Graduates' Employment status, the raw differential wages among STEM and non-STEM graduates five years past degree completion is $16.4 \%$ (1,571 vs 1,350 euros) (Amalaurea, 2018), that reacheas a gap of more than 500 euros when one compares wages of graduates in engeneering with those of graduates in psychology (1,762 vs less than 1,200 euros) (Amalaurea, 2019).
} 
A distinguished feature of our study is the use of information on students' field of qualification at two points in time: at completion of high school and of university, respectively. Exploiting the non-negligible variability in field of studies across the two educational stages, we resort to a fixed effect strategy and are able to identify changes across time in intergenerational coefficients controlling for any unobserved student level time-constant characteristics. This is a non trivial approach in intergenerational studies which allows us to explore whether the influence of parents increases or diminishes at the university stage with respect to the high school one.

Our findings document a sizeable role of parents' educational qualification in STEM fields and heterogenous effects according to the gender of the parent, the gender of the student and the educational stage (high school or university). The estimated intergenerational persistence in STEM field of study at university is only partially attributable to the student field choice in high school and to parental influence on this intermediate choice. Fathers exert a larger influence than mothers do on university completion, not on high school completion, for which both parents appear similarly important. Female and male students, however, are differently affected by each parent at university and at high school. At University, STEM educated fathers appear more important for their sons than for their daugthers, whereas STEM educated mothers matter more for female students. At high-school, instead, females are more sensitive than males to the influence of each STEM educated parent. The fixed effects estimates confirm the differential role of STEM graduate parents at university with respect to high school: the importance of the father increases across different educational stages, getting closer to labour market entry, while that of the mother diminishes. Interestingly, these effects are found to be driven by same gender interaction (father-son, mother-daughter). When we allow for interdependent parents' STEM education effects we spot non-trivial interactions confirming the prominent role of father's field of education with respect to mother's on university completion and revealing a mother-daughter relationship.

Our paper is the first to identify a large set of heterogeneous intergenerational STEM education parameters and represents an important preliminary step to isolate causal links, highlighting that there is room to promote gender equality also within the household. The results that exploit the longitudinal dimension of the data are fully consistent with the results 
that do not control for unobserved student characteristics, and are robust to a number of sensitivity checks. Moreover, we provide evidence that our intergenerational associations are not explained by the transmission of liberal profession of parents for most of STEM fields, while they are driven by some non-STEM fields (economic and legal studies), consistently with a mechanism which has been spotted by Aina and Nicoletti (2018) in Italy. A less conservative view of our results could thus interpret our estimates as causal. We discuss the issue in more detail in the paper.

The paper is structured as follows. Section 2 contains a short review of the recent literature on the determinants of STEM educational outcomes. Section 3 illustrates the data, the process of classification of the parents' degree and describes the sample we use. Section 4 describes our empirical strategy. Section 5 presents gendered results of the intergenerational analysis of STEM versus non-STEM educational outcomes. In Section 6 the role of parental liberal professions in the intergenerational transmission is explored, looking at the specific field of study of parents and children. Section 7 concludes and highlights policy implications.

\section{Background literature on STEM education}

Several recent papers have studied the determinants of students' STEM field choice at university. The possible factors standing as influencial range from peer effects (Anelli and Peri, 2019) to sibling gender composition (Brenoe, 2018; Oguzoglu and Ozbeklik, 2016), previous science exposure (De Philippis, 2017; Gottfried and Bozick, 2016), information bareers (Barone et al., 2017), beliefs and expectations (Wiswall and Zafar, 2015), and sociocultural

background measured by conservative political and religious attitudes (Grossmann et al., 2016).

In parallel, researchers are increasingly analysing the drivers of the gender gap in STEM university entry and completion. High school STEM readiness and scientific content and pre-college math ability have been found to be strong predictors of such gap in different countries (see Card and Payne (2017) and Saltiel (2019) for the US, Delaney and Devereux (2019) for Ireland, Granato (2018) for Italy). An opposite conclusion is reached by Justman and Méndez (2018) for Australia. The proportion of high school female peers is estimated 
to widen gender differences in STEM higher education in Denmark (Brenoe and Zolitz, 2018), while peer quality at high school has been proved to have persistent effects on college outcomes for girls in China, where girls doing well in mathematics seem to encourage female classmates to pursue a STEM track (Mouganie and Wang, 2019). Having being assigned to female advisors during the first year of college is estimated to narrow the gender gap in STEM enrollment and graduation in Lebanon (Canaan and Mouganie, 2019).

Other papers reveal the existence of gender differences in the persistence in STEM education and analyse their sources (Ehrenberg, 2010; Fischer, 2017; Griffith, 2010; Isphording and Qendrai, 2019). Griffith and Main (2019) find that gender diversity in the first year of engineering improves all students' propensity to continue.

A related stream of studies focuses on the gender gap in math performance (Contini et al., 2017), emphasizing cultural explanations (Guiso et al., 2008; Nollenberger et al., 2016), and the impact of teachers' gender stereotypes (Carlana, 2019).

The evidence on the role family background and parental education in shaping STEM educational outcomes and their gender gap is instead very scarce. To the best of our knowledge, one exception is Granato (2018) which investigates the early determinants of the STEM gender gap in Italy using previous waves of the Almalaurea dataset. She finds that parental social status and education are positively associated with the probability of achieving a STEM degree. While abstaining from an intergenerational transmission perspective, her paper embedds cross sectional positive estimated associations between parental and children STEM education, at both university and high school stages, which are consistent with the findings we present in the next sections.

\section{Data and sample selection}

This study relies on the most recent wave of the AlmaLaurea ${ }^{3}$ survey: the 2017 cohort of graduates from Italian universities (XX Survey "Profilo dei Laureati"). 74 universitites

\footnotetext{
${ }^{3}$ AlmaLaurea is an Italian Interuniversity Consortium established in 1994 with the objective of conducting statistical studies on the Italian university system. AlmaLaurea runs surveys anually on the Profile of the graduates ("Profilo dei Laureati") and their Employment status after 1, 3 and 5 years ("Condizione occupazionale dei Laureati").
} 
participated in the survey, covering about $90 \%$ of all Italian graduates. The response rate was above $92 \%$, with a total of 255,269 students.

We focus on students who completed high school in Italy, enrolled and graduated under the most recent system ("nuovo ordinamento", namely degrees obtained after the 1999 reform, the so called Bologna process). We retain both students who graduated from a 3-years cycle degree (i.e. "Laurea") as well as students who graduated from a 5-years cycle degree (i.e. "Laurea magistrale a ciclo unico") with no missing values on all covariates used in the empirical analysis. We end up with a large final sample of 155,603 records, out of which approximately $61 \%$ are female students. The dataset includes both administrative and survey information. Administrative data cover information on the students' university degree, including the field of study. Survey data cover information on high school degree (including field of study) and parental background.

STEM skills supply is defined as degree awarded in Science, Technology, Engineering and Math at the tertiary level. However, no common and detailed definition of which fields of study constitute STEM core disciplines is available. We use the definition provided by the EU Comission in 2015, based on Eurostat's Classification of Fields of Education and Training (1999) and modify it to adhere to the up-to-date classification provided by the latest revision of the International Standard Classification of Education (2013). More details on the classification adopted are provided in Appendix A and a detailed list of the disciplines that make up STEM fields can be found in Appendix A.1.

The Almalaurea dataset provide self-reported data (by students) on parents' degree titles, crucial for our analysis. These data do not undergo any cleaning or standardization by the Almalaurea team and the resulting heterogeneity in inserted degree titles is large. A contribution of this paper is the coding from text of the parents' degrees and their classification into STEM/non-STEM through an own-built procedure we describe in Appendix A.2.

Besides the university field of study, we consider the field of the high school degree previously achieved by the student. We categorized the secondary education qualifications considering as STEM qualifications degrees from scientific high schools and selected technical high schools based on high mathematical/technical content of the curriculum. All the remaining high schools are categorized as non-STEM (more details in Appendix A.3). 
Table 1 reports descriptive statistics on our working sample. Among graduates, approximately $23 \%$ choose a STEM degree at university and $52 \%$ choose a STEM degree at high school. The highest shares of parents of these graduates correspond to completion of secondary education (fathers: 46\%; mothers: 51\%) and differences in the share of fathers and mothers holding a tertiary education qualification are minor, despite more fathers than mothers hold STEM degree and the opposite is true for non-STEM degrees. Students raised in families where both the father and the mother hold STEM degrees make up $1 \%$ of the graduates, whereas approximately $7 \%$ of them is raised in families where both parents hold a non-STEM degree. The largest share of students in our sample come from families where both parents have at most high school qualifications (approximately 29\%), followed by families where both parents have junior high school qualifications or less (approximately 19\%). The share of students with at least one parent holding tertiary education, on which we rely for the identification of STEM education intergenerational transmission, is approximately $30 \%$.

Table 2 presents descriptive evidence on the persistence of STEM degree qualifications among students: about $90 \%$ of those who obtain a non-STEM degree at high-school, do so also at university (and the share reaches about $92 \%$ for female students). However, the persistence of field of study is substantially reduced when one considers students who qualify with a STEM degree at high school: only $35 \%$ of them graduates in a STEM degree also at university and this fraction decreases to $26 \%$ for female students. Overall, we observe a sizeable transition from a STEM degree at high school to a non-STEM degree at university - about 35\% of students, and a less likely reverse type of transition - about $5 \%$ of students. We exploit this non-negligible variability in field choice over time in our empirical analysis to control for any unobserved student level factor fixed over time while examining how intergenerational persistence of field choice evolves between high-school and university.

\section{Empirical strategy}

We start examining the intergenerational persistence in the field of qualification at university and at high school by estimating with OLS the parameters of equation (1) and equation (2) 
below. ${ }^{4}$

$$
\begin{aligned}
& S T E M_{i 2}=\alpha_{0}+\sum_{f} \alpha_{f .} F E d u_{f .}+\sum_{m} \alpha_{. m} M E d u_{. m}+\alpha_{X}^{\prime} X_{i}+\varepsilon_{i 2} \\
& S T E M_{i 1}=\lambda_{0}+\sum_{f} \lambda_{f .} F E d u_{f .}+\sum_{m} \lambda_{. m} M E d u_{. m}+\lambda_{X}^{\prime} X_{i}+\varepsilon_{i 1}
\end{aligned}
$$

where $S T E M_{i 2}$ denotes a dummy taking the value 1 if student $i$ graduates from a STEM field at university and 0 otherwise and $S T E M_{i 1}$ denotes the corresponding variable that describes the field of graduation for the same student at high school; $F E d u_{f .}, M E d u_{. m}$ $f, m \in\{1,2,3,4\}$ are dummy variables denoting the qualification level of fathers and mothers respectively, where $f=1(m=1)$ if the father (mother) has a STEM-degree qualification, $f=2(m=2)$ if the father (mother) has a non-STEM degree qualification, $f=3(m=3)$ if the father (mother) has a high school (HS) qualification ${ }^{5}$ and $f=4(m=4)$ if the father (mother) has a junior high school (JHS) qualification or less (reference category in our regression specification). We experimented with different set of control variables in $X_{i}$. In the baseline regressions these controls include region of residence, social class and parents' jobs. $^{6}$

The key parameters of interest in equation (1) and (2) are $\alpha_{f .}, \alpha_{. m}$ and $\lambda_{f .}, \lambda_{. m}, f, m \in$ $\{1,2,3\}: \alpha_{f .}, \alpha_{\text {.m }}$ denote the effect of father or mother qualification on the probability that the student completes a STEM university degree with respect to the reference category (JHS), while $\lambda_{f}, \lambda_{\text {.m }}$ denote the analogous effect of father or mother qualification on the probability that the student completes a STEM high school degree. Positive estimates of $\alpha_{1}, \alpha_{.1}$ denote intergenerational persistence of STEM education at university, and we interpret positive estimates of $\lambda_{1}, \lambda_{.1}$ as evidence of intergenerational persistence of STEM education at high school. The difference $\alpha_{1 .}-\alpha_{2 .}\left(\alpha_{.1}-\alpha_{.2}\right)$ represents the diffential effect of having a father (mother) holding a STEM degree with respect to a father (mother) holding

\footnotetext{
${ }^{4}$ We consider linear probability models to ease interpretation given the large number of interdependent effects we allow for in some of the specifications.

${ }^{5}$ Our primary data source lacks information on field of study at high school (HS) for parents.

${ }^{6}$ All regressions include the following set of controls: region of residence, social class (upper class, middle class and lowerclass - the reference category) and parents' jobs,i.e. a set of dummy variables which distinguish between self-employed workers, entrepreneurs, liberal professionals, managers, teachers, white collars, blue collars and stay-at-home with blue collars being the reference category.
} 
a non-STEM degree. Similarly, $\lambda_{1}-\lambda_{2} .\left(\lambda_{.1}-\lambda_{.2}\right)$ represents the corresponding effect on completing a STEM high school.

Interactions among parents within the household might not be trivial, thus we also consider alternative specifications where our key regressors identify all possible combinations of parental education levels. We define $P E d u_{f m} f, m \in\{1,2,3,4\}$, a set of mutually exclusive dummy variables taking the value 1 if the qualification of the father is $f$ and the qualification of the mother is $m$. For instance, $P E d u_{11}$ takes the value 1 if both parents hold a STEM university degree qualification, and 0 otherwise; while $P E d u_{12}$ takes the value 1 if the father holds a STEM university degree qualification and the mother holds a non-STEM university degree qualification, and 0 otherwise. Specifically we estimate also equations (3) and (4), where $\beta_{f m}\left(\psi_{f m}\right)$ denote the differential effect of having a father with qualification $f$ and a mother with qualification $m$ on the probability of completing a STEM university degree (a STEM high-school degree) with respect to the case in which both parents hold a qualification equal or lower to a junior high school degree:

$$
\begin{aligned}
& S T E M_{i 2}=\beta_{0}+\sum_{m, f} \beta_{m f} P E d u_{m f}+\beta_{X}^{\prime} X+\zeta_{i 2} \\
& S T E M_{i 1}=\psi_{0}+\sum_{m, f} \psi_{m f} P E d u_{m f}+\psi_{X}^{\prime} X+\zeta_{i 1}
\end{aligned}
$$

We exploit the longitudinal dimension of the data, specifically the fact that we observe the same student first completing high school, and later completing university, to control for time-invariant unobserved factors that may be related to parental qualifications and at the same time affect student qualifications and estimate the following fixed effect specification:

$$
\begin{aligned}
S T E M_{i t}= & \sum_{f} \gamma_{f .} F E d u_{i, f .}+\sum_{f} \Delta \gamma_{f .} F E d u_{i, f .} 1(t=2)+\sum_{m} \gamma_{. m} M E d u_{i, . m} \\
& +\sum_{m} \Delta \gamma_{. m} M E d u_{i, . m} 1(t=2)+\gamma_{X}^{\prime} X_{i}+\Delta \gamma_{X}^{\prime} X_{i} 1(t=2)+\alpha_{i}+\nu_{i t}
\end{aligned}
$$

where $1(t=2)$ denotes a dummy variable taking the value one in period 2 , and 0 otherwise. Since in our case, we have a balanced sample with two observations per subject $(T=2)$ and all the key regressors are time-invariant, the specification above is equivalent to estimate equation (6): 


$$
\Delta S T E M_{i 2}=\sum_{f} \Delta \gamma_{f .} F E d u_{i, f .}+\sum_{m} \Delta \gamma_{. m} M E d u_{i, . m}+\Delta \gamma_{X}^{\prime} X_{i}+\Delta \nu_{i, 2}
$$

where $\Delta \gamma_{f .}=\alpha_{f}-\lambda_{f} . \quad \forall f \in\{1,2,3,4\}$ for the effects of fathers' qualifications and similarly for the effect of mothers' qualifications $\Delta \gamma_{. m}$. Indeed, one can view the specification in equation (6) as a difference-in-differences estimator. ${ }^{7}$

It can be easily shown that in a general set-up with time-varying regressors of interest (say, parental investments) and time-varying coefficients, the variability over time in the outcome $S T E M_{i t}$ could be driven by: (a) the change in the impact of a given parental investment over time; and (b) the change in the amount of parental investment over time. With time-varying parental investments measures one could in principle identify and estimate both the variation in the effect of a given parental input in time 2 and time 1 and the effect of a given parental input at time 1. However, in our context, we can rely on time-invariant measures that, net of our controls, could be interpreted as proxies for parental role models. As a consequence, the fixed effect identification strategy illustrated above allows to address the question of whether the effects of parental field of study are stronger at university or at high school. At the same time, it does not inform about the absolute magnitude of either of these effects.

To disentagle the effects that parental field of education exert at high school - and then propagate to the choice of the university degree and its completion - from those exerted directly on university graduation we also estimate equation (7)

$$
S T E M_{i 2}=\delta_{0}+\sum_{f} \delta_{f .} F E d u_{f .}+\sum_{m} \delta_{. m} M E d u_{. m}+\delta_{H S \_S T E M} S T E M_{i 1}+\delta_{X}^{\prime} X_{i}+\omega_{i 2}
$$

where $\delta_{f .}, \delta_{. m} \forall m, f \in\{1,2,3,4\}$ identify - with some abuse of notation - the "direct" effect of father and mother education, respectively, on the choice of a STEM degree at

\footnotetext{
${ }^{7}$ In our setting, with time-invariant regressors, in large samples: $\widehat{\Delta \gamma}_{f}^{F E} \approx \widehat{\alpha}_{f}^{O L S}-\widehat{\lambda}_{f}^{O L S}$. In other words, the fixed-effect estimator on a balanced panel with time invariant regressors is equivalent to the differencein-differences estimator in equation (6), i.e. to the difference in the OLS estimators at the two stages of education in equation (1) and in equation (2). All these estimators for the difference in the impact of intergenerational persistence at the two stages of education -namely high school and university- are not affected by time-invariant individual unobserved heterogeneity.
} 
university. Indeed, one can relate the parameters of equations (1), (2) and (7) as follows: $\alpha_{f .}=\delta_{H S_{-} \text {stem }} \lambda_{f .}+\delta_{f .}, \forall f \in\{1,2,3,4\}$, for father education. The same can be done for mother education. ${ }^{8}$ The so-called total effect of father qualification $\alpha_{f}$. on the probability that the child completes a university degree in STEM is the sum of the direct effect exerted on university completion $\delta_{f}$. and the indirect effect exerted through parental influence on a STEM high school completion $\delta_{H S_{-} s t e m} \lambda_{f}$. If the true value $\delta_{H S_{-} s t e m}$ where zero, there would be no linear dependence between the completion of STEM degree at high school and a STEM degree at university and the possibility of indirect effects - ceteris paribus - of parents through this specific channel would be ruled out. When $\delta_{H S_{-} \text {stem }} \neq 0$, the relative magnitude of the indirect effect through this specific channel depends on the size of $\lambda_{f}$, namely the intergenerational transmision of STEM field qualifications at high school.

\section{Evidence on intergenerational transmission of STEM field qualifications}

The OLS estimates of the coefficients of the STEM Degree equation (1) are displayed in Table 3, while Table 4 presents estimates of equation (3), where interdependent effects between parents are allowed for. Table 5 and Table 6 presents the OLS estimates of the coefficients of the STEM High School (HS) equations with independent and interdependent parents' effect respectively (corresponding to equations (2) and (4)).

Inspection of Table 3 reveals several interesting patterns. The effects ot parents' qualification on the probability of achieving a STEM University degree appears as a sizeable one. The role of fathers and mothers in determining the University outcome of their offprings differs according to their field of study. Having a father with a STEM degree -compared to a JHS father- makes about 15 p.p. for his child to achieve a STEM field degree - a magnitude that would almost counterbalance the observed gender gap in STEM degree completion in our sample. The estimated differential effect of a STEM graduated father with respect to a non-STEM graduated father $\left(\alpha_{1 .}-\alpha_{2}\right)$ is even larger, about 17 p.p.. STEM educated moth-

\footnotetext{
${ }^{8}$ It follows also that $\Delta \gamma_{f} .=\left(\delta_{H S_{-} s t e m} \lambda_{f} .+\delta_{f .}\right)-\lambda_{f .}, \forall f \in\{1,2,3,4\}$, for instance for father education, where $\Delta \gamma_{f}$. are the parameters in equation (5). The same can be done for mother education.
} 
ers are found to be less influential than STEM educated fathers on their offspring's university outcome: their positive effects are about 11 p.p. when compared to JHS mothers, and 9 p.p. when compared to non-STEM mothers. Moreover, the influence of each parent differs across student's gender. STEM educated fathers appear more important for sons, whereas STEM educated mothers are more important for daughters, as testified by the statistically significant gender gaps estimated for $\alpha_{1}$. and $\alpha_{.1}$ (positive for fathers and negative for mothers). It can also be noticed that non-STEM graduated fathers influence negatively the probability that their sons, but not their daughters, achieve a STEM degree, while non-STEM graduated mothers seem to encourage their daughters, but not their sons, to follow STEM tracks. As a result, looking at the differential effect across STEM and non-STEM parental degree, STEM educated fathers appear much more relevant for sons, whereas STEM educated mothers are similarly important for daughters and sons (see the statistically significant 9 p.p. gender gap for $\left(\alpha_{1}-\alpha_{2}\right)$ and the unsignificant one for $\left(\alpha_{.1}-\alpha_{.2}\right)$ in the bottom part of the table).

In order to rule out that these intergenerational effects of STEM education are driven by some specific fields of study of the parent, we replicated the estimation of equation (1) on the subsamples obtained leaving out each of the sixteen parental field of study, considering the same fields listed in Appendix A.1 for students. The estimated coefficients were very little affected, as shown in Table Online Appendix - 6 in the Online Appendix, where we report only the few coefficients exhibiting a change greater than 2 p.p. when a specific parental field was excluded. As an additional robustess check, we re-run the estimation classifying Health Studies among STEM fields for both parents and students, as sometimes done in the literature (see the discussion in Appendix A), and found very similar results.

When we turn to the previous educational stage, in Table 5, we uncover a different scenario: STEM high school outcomes appear similarly affected by fathers' and mothers' field of study. Indeed the effect of a STEM graduated parent versus a JHS qualified one is about 12 p.p. and that of a STEM parent versus a non-STEM one is about 10 p.p. regardless of the parent's gender. Moreover, in this adolescence period females are documented to be generally more sensitive than males to parental influence: all gender gaps are estimated to be negative. In particular, both gender gaps in $\lambda_{1}$ and $\lambda_{.1}$ are negative and significant, indicating that girls react more than boys to both STEM father's and mother's example. 
In Table 4 the intergenerational coefficient of each parent is allowed to vary across the educational level of the other parent. Scrolling through the first column, we notice that the influence of STEM fathers prevails on the influence of STEM mothers. With respect to a student whose parents both hold a STEM degree, the probability that a student graduates in STEM at university decreases of about $9(\approx 26-17)$ p.p if the mother holds a nonSTEM degree, while it decreases twice as much, i.e. of about $18(\approx 26-8)$ p.p. if it is the father that holds a non-STEM degree. Moreover, the prominent role of fathers occurs for both sons and daughters, while STEM mothers' role model reaches mainly daughters. Table 6 confirms the more equal role of both parents for high school achievements, with STEM mothers stimulating STEM studies of their offsprings even in the presence of a non-STEM father. The negative and statistically significant student gender gaps (in all cases but those in which the mother is low educated) describe again girls as more affected by parental influence than their males counterparts in this phase of their life.

Table 7 displays the fixed effects coefficients corresponding to equation (5), which identify -net of time constant unobserved heterogeneity- the change in intergenerational transmission across the two educational stages we observe. These results point to effects that are gendered along both the parent's and student's dimensions. Indeed, the role of STEM fathers versus their JHS counterparts in determining the student's STEM outcome is stronger for higher education than for high school (the effect significantly increases of approximately 3 p.p.), while the role of STEM mothers does not appear to change significantly over time. This is coherent with the view that fathers take a prominent role for children as they approach their entrance into the job market. However, as it can be observed in the last column, the gender difference in the time variation of the intergenerational coefficient is significant for both parents and it moves according to same-gender interactions: STEM fathers become more influencial for the STEM outcomes of their sons -but not of their daughters, while STEM mothers loose the role model they exerted for their daughters in adolescence. The effects of STEM versus non-STEM parent in the bottom part of the table also exhibit a same-gender pattern.

Table 8 conveys the same tipe of evidence allowing for interdependent effects, which show again - similar to their OLS counterparts in previous Table 4 - the prevaling weight of STEM 
fathers with respect to STEM mothers.

Finally, we estimate equation (7), through which we decompose the effects that parental qualification exerts at university and at high school. Results are reported in Table 9. Consistently with descriptive statistics reported in Table $2, \delta_{H S \_S T E M}$ is statistically significant: students who complete a STEM field high school are generally more likely (about 25 p.p.) to complete a STEM field degree at university in the pooled sample. ${ }^{9}$ The indirect effect is small and only proportional to the total intergenerational transmission of STEM: for instance, in the pooled sample it implies a 3 p.p. increase $(100 \cdot 0.25 \cdot 0.13)$ in the probability to complete STEM at University for students with a STEM graduate father and having completed a STEM high school. The effect of parental STEM education qualifications is only partially mediated by what happens at high school: the "direct" effect of father and mother education on the choice of a STEM degree at University (with respect to JHS) is reflected in the sign and magnitude of the estimates of coefficients $\delta_{f .}, \delta_{. m} \forall m, f \in\{1,2,3\}$, respectively. Similarly to what we observe in Table 3, we find that parental field of study matters: STEM graduate fathers lead to 12 p.p. increase in the probability of graduating in STEM fields, compared to a lower increase of 8 p.p. in the case of STEM graduate mothers. Notably, all these estimated "direct" effects remain statistically significant and are only slightly lower ( $20 \%$ for fathers, $25 \%$ for mothers) than the total effects estimated in Table 3 where we do not control for STEM high school completion. ${ }^{10}$ Figures 1, 2, 3 offer a visual representation of the relative size of total, direct and indirect effects in the pooled sample, in the sample of male and in the sample of female students, respectively. It is apparent that the direct effects exert a major role. ${ }^{11}$

We depart from the estimation of equation (7) to check the robustness of our intergenerational parameters to the inclusion of additional student's characteristics observable at

\footnotetext{
${ }^{9}$ Interestingly, the STEM high school effect is about 28 p.p. for males and 17 p.p. for females, confirming the lower persistence of females in STEM fields.

${ }^{10}$ The bottom part of Table 9 show that also the "direct" effect of STEM versus non-STEM education are marginally lower with respect to their total effect counterparts in Table 3.

${ }^{11}$ Table Online Appendix - 1 in the Online Appendix allows for both the mediating role of high school and interdependent effects of parental education. The results confirm the asymmetric behaviour of STEM university completion in response to father and mother field of education detected in Table 4 and the prevalence of the direct effects. The Online Appendix is available at: https://sites.google.com/site/chiaramonfardiniwebpage/home/research.
} 
university, but not at high school: the location of the university with respect to the region of residence, the type of high school completed, information on academic and work values reported by students as being important in choosing their university degrees. The OLS estimates of the coefficients of equation (7) with enhanced controls are available in the Online Appendix in Table Online Appendix - 2. They reveal that the effect of father's and mother's STEM education on the probability that the child graduates in STEM at university remains mostly stable with respect to the results in Table 3 even with the insertion of additional controls. $^{12}$

\section{On the role of parental (liberal) professions}

Aina and Nicoletti (2018) study the intergenerational transmission of liberal professions and find that fathers exert a prominent role. The same authors also document the importance of intergenerational transmission of formal education for some of the compulsory steps required to become a liberal professional. Prompted by this intriguing results in the literature and the consistency with our own findings on the intergenerational transmission of STEM education (see Section 5), we explore whether our results are driven by intergenerational transmission of liberal professions. To do so, we augment equation (1) with the interaction of parental qualifications with a dummy variable capturing whether the parent is a liberal professional. ${ }^{13}$ Results are reported in Table 10. With some abuse of notation, we use $\alpha_{f .}, \alpha_{. m} f, m \in$ $\{1,2,3,4\}$ to denote the effects of parental qualifications when the parent is not a liberal professional. The coefficients $\alpha_{L 1}, \alpha_{L 2}, \alpha_{L 3}, \alpha_{L 4}$. denote the differential influence on the probability of graduating in a STEM field of father's qualifications when the father is a liberal professional; similarly $\alpha_{L .1}, \alpha_{L .2}, \alpha_{L .3}, \alpha_{L .4}$ denote the differential influence of mother's qualifications when the mother is a liberal professional.

\footnotetext{
${ }^{12}$ Table Online Appendix - 4 in the Online Appendix contains the estimates obtained when we also add the high school final mark to the list of controls. As before, the estimates of the intergenerational correlation of parents' and child's education do not vary considerably. Similarly, the pattern of the interdependent effects is not sensitive to the inclusion of the additional controls, see Table Online Appendix - 3 and Online Appendix - 5 in the Online Appendix.

${ }^{13}$ In addition to the controls listed in footnote 6 , we now include the interaction of the binary indicator for liberal profession and the educational dummies of the parents. The observed frequency of liberal professionals in our sample is $15 \%$ of fathers and $5 \%$ of mothers.
} 
While the STEM-field intergenerational persistence at university proves not to be closely related to having parents who are liberal professional, we find that the influence of non-STEM graduate parents is mainly driven by those who are liberal professional and concentrated on sons. We document a different role of fathers' and mothers' occupations with field of qualification depending on student gender: both liberal professional STEM graduate fathers and mothers increase the likelihood of the daugther graduating from a STEM field, while they exert negligible differential effect for sons. On the contrary, liberal professionals nonSTEM graduate fathers significantly reduce the probability of the offspring completing a STEM degree, more for sons than for daughters. Liberal professional non-STEM mothers exert negligible roles for daughters and tend to reduce the probability of graduating from a STEM field only for sons.

The empirical evidence corroborating the statements above comes from the figures reported in Table 10. Specifically, the differential influence of parents holding a liberal profession within a specific field of graduation is statistically significant for STEM graduate liberal professional fathers and mothers and it amounts to about a 3 p.p. increase with respect to the positive intergenerational transimission of STEM education between fathers and children (14 p.p.) and mothers and children (10 p.p.). This result is driven by a differential effect on daughters $\left(\alpha_{L 1}=0.04\right.$ for fathers, $\alpha_{. L 1}=0.05$ for mothers $)$, while no statistically significant differential effect of holding a liberal profession can be detected for sons. Conversely, non-STEM graduate liberal professional fathers tend to reduce the probability that children graduate in STEM. This effect is 6 p.p. larger in absolute terms with respect to the effect for non-STEM graduate fathers who are not liberal professional. While non-STEM graduate mothers who are not liberal professional tend to positively affect the probability that children graduate in STEM, this positive effect vanishes for non-STEM graduate mothers who are liberal professional $(=0.0271-0.0267=0.004)$. Notably, the result in the pooled sample is only driven by daughters for non-liberal professional mothers and by sons for liberal professional mothers, with statistically significant differences along the gender of the child. Our results are consistent with the view that the intergenerational transmission of the non-STEM liberal profession happens more for sons than for daughters: in Table $10 \widehat{\alpha}_{L 2}$. (non-STEM graduate liberal professional fathers) is -0.11 for males and -0.03 for females; 
$\widehat{\alpha}_{L .2}$ (non-STEM graduate liberal professional mothers) is -0.06 for males and 0 for females.

If entry barriers into liberal professions are higher in non-STEM liberal jobs (e.g. notary or lawyer) compared to STEM liberal jobs (e.g. engineer), this finding would be in line with the discussion by (Aina and Nicoletti, 2018, Tab.1, pg.111), who suggest that "high entry barriers into the profession increase the occupational transmission from fathers to children" and find that "non-graduate liberal professionals transmit to their child a level of formal human capital similar to the blue-collars' one and lower than the entrepreneurs' one" (see pg.115).

In short, the findings described above reveal interesting intergenerational transmission paths, but they show that our intergenerational correlations of STEM qualifications are not driven by the transmission of liberal profession.

One might wonder whether these results are driven by one specific field, rather than by STEM or non-STEM fields. We address this issue relying on the estimates of multinomial logit models where we let the probability that the child graduates in a specific field depend on the field and qualification of the mother and of the father (see appendix A.1 and A.2 for the definition of the ten broad fields of study we consider for students and parents). For this analysis, we rely on the pooled sample of male and female students, to avoid overparametrization and ease the interpretation of the results. The multinomial logit probabilities are specified as:

$$
\begin{aligned}
\operatorname{Prob}\left(\text { Field }_{i k}=k \mid X_{i}\right)= & \Lambda\left(\sum_{l} \mu_{f, l} \text { F_Field }_{i l}+\mu_{f, l}^{L} \text { F_Field }_{i l} * F_{-} \text {Lib }_{i}+\right. \\
& \left.\mu_{m, l} M_{-} \text {Field }_{i l}+\mu_{m, l}^{L} M_{-} \text {Field }_{i l} * M_{-} \text {Lib }_{i}+\mu^{\prime} Z_{i}\right)
\end{aligned}
$$

where $i$ denotes the child, $k$ denotes child field, $l$ denotes parent field, $M_{-} F_{i e l} d_{i l}$ and $F \_F i e l d_{i l}$ are mother and father field respectively, $F_{-} L i b_{i}$ and $M_{-} L i b_{i}$ are dummies for father and mother holding a liberal profession and $Z_{i}$ includes the same set of variables listed in footnote 4 and dummies for parental qualification lower than University.

Striking patterns emerge when we explore the heterogeneity by each parental field and liberal professions. Figures 4, 5, 6 report the average partial effects (APEs in what follows) of the parental field of study on the probability that a child graduates in a specific field, resulting from the multinomial logit model estimates. In each figure, rows differ with respect 
to the outcome considered, namely te probability that the child graduates in one specific field; columns report APEs of different regressors: the left column report the APEs for father's field of study while the right column report the APEs for the mother's field of study. In each panel of each Figure, the light gray shaded areas highlight parental STEM fields, while the vertical dashed red bar stresses the APE for the case in which parent and child graduate in the same field. Additionally, 95\% confidence intervals for each APE are reported, with bars of different gray intensity as illustrated in the legend of the Figure. We first examine the consistency between field of graduation of parents and children: this is strong, a somewhat unexpected finding at this relatively high field-disaggregation level. For non-liberal fathers in 10 out of 10 cases, the highest APE is observed when there is concordance in field and the figures change only slightly for liberal fathers ( 8 out of 10 cases; 9 out of 10 if one aggregates STEM vs non-STEM fields). A similar level of consistency is observed for mothers. For mothers, the highest APE is observed when mother and child share the same field: 8 out of 10 cases for non-liberal workers (10 out of 10 aggregating fields into STEM and non-STEM) and a somewhat smaller share for liberal workers ( 5 out of 10 but 8 out 10 aggregating fields into STEM and non-STEM). These findings suggest that the intergenerational transmission we observe is indeed occurring by field, and results in high persistence of rewarding in (the labour market) STEM fields across generations.

We now turn to the detailed analysis of the role of liberal professions by field.

Figure 4 shows that for most of the STEM fields of (child) graduation, there is little heterogeneity by liberal profession when parents graduate in the same field. Some differences emerge instead considering other-STEM fields. These fields might offer the possibility to work as biologist or as architect. While we cannot split the aggregate further, due to sample size restrictions, we do observe that for this residual STEM-field aggregate the role of liberal professional parents is not negligible, as the APEs are higher when mothers (or fathers) graduate in the same field and hold a liberal profession (about 6 percentage point higher for both mothers and fathers).

Figures 5 and 6 allow us to address the same issue for non-STEM fields of (child) graduation and confirm the pattern we previously documented through linear probability models estimates. There is indeed substantial evidence of intergenerational transmission of field 
being partly driven by liberal professions: in economical fields the gap in APEs for liberal vs non-liberal parents is as high as 10 percentage points for mothers (APEs are 0.06 for non-liberal and 0.16 for liberal workers graduated in this field) and 18 percentage points for fathers (APEs are 0.08 for non-liberal and 0.26 for liberal workers graduated in this field); in legal fields the gap becomes 20 percentage points and 9 percentage points for fathers and mothers respectively (APEs are: for fathers, non-liberal 0.12 and liberal 0.32; for mothers, non liberal 0.048 liberal 0.14 ), while in the residual aggregate of other non-STEM fields the gap is 10 percentage points for fathers and 14 percentage points for mothers (APES are: for fathers, non-liberal 0.026 liberal 0.13; for mothers, non-liberal 0.002 liberal 0.14). Economical fields give access to positions like professional accountant or businness accountant, while graduates in legal fields tend to become lawyers or notary. Due to small sample size, we cannot disentagle fields within the non-STEM aggregate. Fields included in this aggregate may allow access to professions such as chemists, veterinary surgeons or agronomist and phycologist. The non-STEM aggregate includes also fields like teaching, physical education and defense and security. Finally, for the literary field we do also observe slighly higher APEs for parents holding a liberal job and this pattern could be attributed to professions like journalist, pressman or radio/tv reporter.

In short, the intergenerational transmission by field documented through the multinomial logit model estimates is high and not driven by liberal profession for most of the STEM fields, notably scientific and engeneering for fathers, while it seems largely driven by liberal profession of parents in some non-STEM fields, specifically economical and legal studies. This finding is consistent with previous evidence in the literature (Aina and Nicoletti, 2018) and with the existence of entry barriers in some professions.

\section{Concluding remarks}

The paper documents the presence of sizeable intergenerational transmission of STEM education in Italy at both the high-school and university level and a more prominent role of fathers' field of qualification with respect to mothers' at the stage of the educational career closer to labour market entry: while at high school parents exert a similar role, at university 
the influence of STEM graduate fathers generally prevails on the influence of STEM graduate mothers. The stronger role of fathers reaches more the sons, while STEM mothers' guidance reaches mainly daughters.

We find that having a father who graduated from a STEM field increases the likelihood of graduating from a STEM field at high school by 13 p.p. (8 p.p. for sons; 13 p.p for daughters) and at university by 15 p.p. (16 p.p. for sons; 12 for daughters). The magnitude of these figures is half of the gender gap in STEM degree completion at high school and almost as large as the gap in STEM university degree completion. The extent of intergenerational transmission is sizeable also for mothers: having a STEM graduate mother increases the probability of completing a STEM high school by 12 p.p. (6 p.p. for sons; 16 p.p. for daughters) and the probability of graduating from a STEM field at university by 11 p.p. (8 p.p. for sons; 12 p.p. for daughters). Exploting the non-negligible variability in STEM field between high-school and university graduation rates, we can also document that, controlling for time-invariant unobservables, the importance of father increases across different educational stages, while that of mother diminishes and that both effects are driven by a same-gender pattern (father-son, mother-daughter).

The intergenerational persistence in STEM is not related to parents holding a liberal professions, while the persistence of non-STEM field completion across generations seems largerly be driven by parents holding a liberal profession. Notably, and somewhat surprisingly, the intensity of the intergenerational transmission of field of qualification at university is sizeable also at a much narrower level of field classification, namely even not grouping fields into STEM and non-STEM. At this more disaggregate level, we show that the differential influence of parents holding a liberal profession, conditional on field of graduation, is highest in the fields of economical and legal studies, where entry barriers to profession are likely to be relevant (Aina and Nicoletti, 2018).

We do not have measures of active parental investments on their offspring and interpret our measures of parental educational qualifications as proxies of time-invariant role models. We believe that the same-gender pattern we spot in most intergenerational associations of fields of study signals the relevance of parental role model and can be considered as indirect evidence supporting our interpretation. Our evidence on the transmission of some non-STEM 
fields through parental liberal profession speaks in favour of channels of intergenerational transmission more related to the transfer of endowments and non-trivial interactions with the institutional setting, as discussed in Section 6 (see the taxonomy reported by Björklund and Salvanes (2010)).

Our findings on the persistence of STEM educational attainments are consistent with previous empirical evidence on intergenerational transmission of education in Italy (Checchi et al., 2013) and we uncover interesting novel patterns that could inform parents and policy makers concerned with the shortage of supply of STEM related skills, particularly among females. Would make parents aware of these patterns, change the investments they make in their offspring? While this paper cannot answer this question due to lack of adequate data, it suggests that parental influence is likely to be an important mediator of impact of interventions that aim at promoting STEM fields targetting middle school and high schools students. Based on our results, we can argue that, while - at least in our sample $-43 \%$ of the students makes the same non-STEM field choice at both high school and university, targetting only middle school students may not be fully effective to promote STEM field completion among females at high school (and at University): at early stages of their educational carreer, students are more sensitive to parental role models and this might attenutate program effects. The question of whether targetting simultaneously also parents, who are potentially less-malleable but, at the same time, not always fully informed and aware of their influence, would improve program effectiveness, is open for further research. It would also be interesting to explore whether programs who promote STEM fields targetting students directly induce the unintended effect of significantly reducing intergenerational transmission of field choice. 


\section{References}

Aina, C., Nicoletti, C., 2018. The intergenerational transmission of liberal professions: nepotism versus abilities. Labour Economics , 108-120.

Amalaurea, 2018. Rapporto 2018 sul Profilo e sulla Condizione Occupazionale dei laureati. http://www.almalaurea.it/. Almalaurea.

Amalaurea, 2019. Rapporto 2019 sul Profilo e sulla Condizione Occupazionale dei laureati. http://www.almalaurea.it/. Almalaurea.

Amin, V., Lundborg, P., OlofRooth, D., 2015. The intergenerational transmission of schooling: Are mothers really less important than fathers? Economics of Education Review , 100-111.

Anelli, M., Peri, G., 2015. Gender gap in Italy: the role of college majors. In: Boeri T, Patacchini E, Peri G (eds) Unexplored dimensions of discrimination. Oxford University Press, London , 79-109.

Anelli, M., Peri, G., 2019. The Effects of High School Peers' Gender on College Major, College Performance and Income. The Economic Journal 129, 553-602.

Barone, C., Schizzerotto, A., Abbiati, G., Assirelli, G., 2017. Gender, information barriers and fields of study choice: a field experiment. SciencesPo WP 63 .

Björklund, A., Salvanes, K.G., 2010. Education and family background: Mechanisms and policies. In: E.A. Hanushek, S. Machin, and L. Woessmann (eds.), Handbook of Economics of Education, Vol. 3, North Holland , 201-247.

Black, S.E., Devereux, P.J., 2011. Recent developments in intergenerational mobility. Handbook of Labor Economics, 4 edn., Elsevier , 1487-1541.

Brenoe, A., 2018. Origins of Gender Norms: Sibling Gender Composition and Women's Choice of Occupation and Partner. Technical Report IZA DP 11692. Institute of Labor Economics.

Brenoe, A., Zolitz, U., 2018. Exposure to More Female Peers Widens the Gender Gap in STEM Participation. University of Zurich, Working Paper No. 285 .

Canaan, S., Mouganie, P., 2019. Female Science Advisors and the STEM Gender Gap. IZA DP No.12415 .

Card, D., Payne, A., 2017. High School Choices and the Gender Gap in STEM. Technical Report NBER WP No. 23769. National Bureau of Economic Research.

Carlana, M., 2019. Implicit Stereotypes: Evidence fromTeachers' Gender Bias. The Quarterly Journal of Economics 134, 1163-1224.

Checchi, D., Fiorio, C., Leonardi, M., 2013. Intergenerational persistence of educational attainment in italy. Economic Letters, 229-232.

Contini, D., Di Tommaso, M., Mendolia, S., 2017. The gender gap in mathematics achievement: Evidence from Italian data. Economics of Education Review , 32-42. 
De Philippis, M., 2017. STEM graduates and secondary school curriculum: does early exposure to science matter? Temi di discussione 1107, Bank of Italy, Economic Research and International Relations Area .

Delaney, J., Devereux, P.J., 2019. It's Not Just for Boys! Understanding Gender Differences in STEM. IZA DP No.12176 .

Ehrenberg, R., 2010. Analyzing the factors that influence persistence rates in STEM field, majors: Introduction to the symposium. Economics of Education Review , 888-891.

EU Skills Panorama 2014, 2015. STEM skills Analytical Highlight. Report prepared d by ICF and Cedefop for the European Commission. European Commission.

European Commission, 2015. Does the EU need more STEM graduates? Technical Report. European Commission Report. Directorate General for Education and Culture.

EUROSTAT, 2017. Gender equality datasets. http://ec.europa.eu/eurostat/web/equality/data/database. EUROSTAT.

Fayer, S., Lacey, A., Watson, A., 2015. STEM Occupations: Past, Present, And Future. Technical Report. US Bureau of Labor Statistics.

Fischer, S., 2017. How classroom composition differentially affects men's and women's STEM persistence. Labour Economics , 211-226.

Goos, M., Hathaway, I., Konings, J., Vandeweyer, M., 2013. High Technology Employment in the European Union. VIVES Discussion Paper. KU Leuven.

Gottfried, M., Bozick, R., 2016. Supporting the STEM Pipeline: Linking Applied STEM CourseTaking in High School to Declaring a STEM Major in College. Education Finance and Policy, MIT Press , 177-202.

Granato, S., 2018. PhD Thesis, Queen Mary University of London .

Griffith, A., 2010. Persistence of women and minorities in STEM field majors: Is it the school that matters? Economics of Education Review , 911-922.

Griffith, A., Main, J., 2019. First impressions in the classroom: How do class characteristics affect student grades and majors? Economics of Education Review , 125-137.

Grossmann, V., Osikominu, A., Osterfeld, M., 2016. Sociocultural Background and Choice of STEM Majors at University. CEPR Discussion Papers 11250 .

Guiso, L., Monte, F., Sapienza, P., Zingales, L., 2008. DIVERSITY: Culture, gender, and math. Science, 1164-1165.

Holmlund, H., Lindhal, M., E., P., 2011. The causal effect of parents' schooling on children's schooling: a comparison of estimation methods. Journal of Economic Literature , 615-651.

Huntington-Klein, N., 2018. College Choice As A Collective Decision. Economic Inquiry , 12021219. 
Isphording, I., Qendrai, P., 2019. Gender Differences in Student Dropout in STEM. IZA Research Reports 87 .

Justman, M., Méndez, S., 2018. Gendered choices of STEM subjects for matriculation are not driven by prior differences in mathematical achievement. Economics of Education Review , 282-297.

Kahan, S., Ginther, D., 2017. Women and STEM. NBER Working Papers 23525.

Mouganie, P., Wang, Y., 2019. High-Performing Peers and Female STEM Choices in School. IZA DP No.12455 .

Nollenberger, N., Rodriguez-Planas, N., Sevilla, A., 2016. The math gender gap: The role of culture. American Economic Review , 257-61.

Oguzoglu, U., Ozbeklik, S., 2016. Like father, like daughter (unless there is a son): sibling sex composition and women's STEM major choice in college. IZA Discussion Paper No. 10052 .

Piazzalunga, D., 2018. The Gender Wage Gap Among College Graduates in Italy. Italian Economic Journal , 33-90.

Ray, R., 2015. STEM Education and Economic Performance in the American States. MPRA Paper 65517, University Library of Munich .

Saltiel, F., 2019. What's Math Got to Do With It? Multidimensional Ability and the Gender Gap in STEM. 2019 Meeting Papers 1201, Society for Economic Dynamics .

Triventi, M., 2013. Stratification in higher education and its relationship with social inequality: a comparative study of 11 European countries. European Sociological Review , 489-502.

UNESCO, 2017. Cracking the code: Girls' and women's education in science, technology, engineering and mathematics (STEM). Technical Report. UNESCO.

Winters, J., 2018. Do higher levels of education and skills in an area benefit wider society? IZA World of Labor .

Wiswall, M., Zafar, B., 2015. Determinants of college major choice: Identification using an information experiment. Review of Economic Studies , 791-824.

World Economic Forum, 2018. Global Gender Gap Report. 


\section{Tables and Figures}

Table 1: Descriptive statistics.

\begin{tabular}{|c|c|c|c|c|}
\hline Variable & Mean & Std. Dev. & Min & $\operatorname{Max}$ \\
\hline female* $^{*}$ & 0.607 & 0.488 & 0 & 1 \\
\hline$S T E M_{2}$ (Degree)* & 0.228 & 0.420 & 0 & 1 \\
\hline$S T E M_{1}(\mathrm{HS})$ & 0.515 & 0.500 & 0 & 1 \\
\hline \multicolumn{5}{|l|}{ Father education } \\
\hline$F E d u_{1}$. (STEM degree) & 0.063 & 0.242 & 0 & 1 \\
\hline$F E d u_{2}$. (Non-STEM degree) & 0.143 & 0.350 & 0 & 1 \\
\hline$F E d u_{3 .}(\mathrm{HS})$ & 0.457 & 0.498 & 0 & 1 \\
\hline$F E d u_{4}$. (JHS or less) & 0.338 & 0.473 & 0 & 1 \\
\hline \multicolumn{5}{|l|}{ Mother education } \\
\hline$M E d u_{.1}$ (STEM degree) & 0.037 & 0.188 & 0 & 1 \\
\hline$M E d u_{.2}$ (Non-STEM degree) & 0.157 & 0.364 & 0 & 1 \\
\hline$M E d u_{.3}(\mathrm{HS})$ & 0.508 & 0.500 & 0 & 1 \\
\hline$M E d u_{.4}(\mathrm{JHS}$ or less $)$ & 0.298 & 0.457 & 0 & 1 \\
\hline \multicolumn{5}{|l|}{ Parents' combined education } \\
\hline$P E d u_{11}$ & 0.012 & 0.108 & 0 & 1 \\
\hline$P E d u_{12}$ & 0.023 & 0.149 & 0 & 1 \\
\hline$P E d u_{13}$ & 0.025 & 0.156 & 0 & 1 \\
\hline$P E d u_{14}$ & 0.003 & 0.056 & 0 & 1 \\
\hline$P E d u_{21}$ & 0.011 & 0.105 & 0 & 1 \\
\hline$P E d u_{22}$ & 0.066 & 0.248 & 0 & 1 \\
\hline$P E d u_{23}$ & 0.058 & 0.234 & 0 & 1 \\
\hline$P E d u_{24}$ & 0.008 & 0.089 & 0 & 1 \\
\hline$P E d u_{31}$ & 0.012 & 0.107 & 0 & 1 \\
\hline$P E d u_{32}$ & 0.056 & 0.230 & 0 & 1 \\
\hline$P E d u_{33}$ & 0.293 & 0.455 & 0 & 1 \\
\hline$P E d u_{34}$ & 0.096 & 0.295 & 0 & 1 \\
\hline$P E d u_{41}$ & 0.002 & 0.045 & 0 & 1 \\
\hline$P E d u_{42}$ & 0.013 & 0.111 & 0 & 1 \\
\hline$P E d u_{43}$ & 0.132 & 0.339 & 0 & 1 \\
\hline$P E d u_{44}$ & 0.191 & 0.393 & 0 & 1 \\
\hline Observations & 159,610 & & & \\
\hline
\end{tabular}

Notes: Source: Almalaurea XIX Profilo dei Laureati survey (2017 cohort of graduates). Sample: 159,610 students who graduated from high school and from university in Italy, from 3-years and 5-years degree cycles with non-missing value of all covariates included in the analysis. Notation: $S T E M_{2}$ takes the value 1 if the individual graduates from a STEM field degree at university; $S T E M_{1}$ takes the value 1 if the individual graduates from a STEM field degree at high school; $F E d u_{i .}, M E d u_{. j}$ $P E d u_{i j} i, j \in\{1,2,3,4\}$ are dummy variables denoting levels of parental education as clarified in the table. Variables marked with * indicate administrative data, unmarked variables indicate survey data. 
Table 2: Persistence of child's field outcome over time (at high schools versus at university): frequency, (row percentage), [column percentage],\{cell percentage $\}$. Pooled, females.

\begin{tabular}{|c|c|c|c|}
\hline \multirow[b]{2}{*}{ STEM field at high school $S T E M_{1}$} & \multicolumn{2}{|c|}{ STEM field at university $S T E M_{2}$} & \multirow[b]{2}{*}{ Total } \\
\hline & 0 & 1 & \\
\hline 0 & 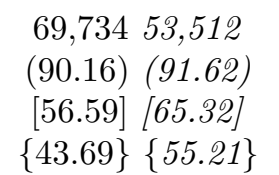 & $\begin{array}{c}7,614 \quad 4,894 \\
(9.84)(8.38) \\
{[20.92][32.65]} \\
\{4.77\}\{5.05\}\end{array}$ & $\begin{array}{rl}77,348 & 58,406 \\
(100.00) & (100.00) \\
{[48.46]} & {[60.26]} \\
\{48.46\} & \{60.26\}\end{array}$ \\
\hline 1 & $\begin{array}{c}53,48428,417 \\
(65.02)(73.79) \\
{[43.41][34.68]} \\
\{33.51\}\{29.32\}\end{array}$ & $\begin{array}{cl}28,778 & 10,095 \\
(34.98) & (26.21) \\
{[79.08]} & {[67.35]} \\
\{18.03\} & \{10.42\}\end{array}$ & $\begin{array}{cl}82,262 & 38,512 \\
(100.00) & (100.00) \\
{[51.54]} & {[39.74]} \\
\{51.54\} & \{39.74\}\end{array}$ \\
\hline Total & $\begin{array}{cc}123,218 & 81,929 \\
(77.20) & (84.53) \\
{[100.00]} & {[100.00]} \\
\{77.20\} & \{84.53\}\end{array}$ & $\begin{array}{cc}36,392 & 14,989 \\
(22.80) & (15.47) \\
{[100.00]} & {[100.00]} \\
\{22.80\} & \{15.47\}\end{array}$ & 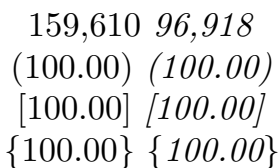 \\
\hline
\end{tabular}

Notes: Source: Almalaurea XIX Profilo dei Laureati survey (2017 cohort of graduates). Sample: 159,610 students who graduated from high school and from university in Italy, from 3-years and 5-years degree cycles with non-missing value of all covariates included in the analysis. 
Table 3: Estimates of the effects of parental education on the attainment of a STEM degree at the university, pooled and by gender of the student.

\begin{tabular}{|c|c|c|c|c|}
\hline & $\begin{array}{c}\text { Pooled } \\
(1) \\
\text { (mean: } 0.228)\end{array}$ & $\begin{array}{c}\text { Males } \\
(2) \\
\text { (mean: } 0.341)\end{array}$ & $\begin{array}{c}\text { Females } \\
(3) \\
\text { (mean: } 0.155)\end{array}$ & $\begin{array}{c}\text { Males-Females } \\
\text { (4) }\end{array}$ \\
\hline \multicolumn{5}{|l|}{ Father education } \\
\hline$\alpha_{1}$ & $\begin{array}{c}0.1534^{* * *} \\
(0.0059)\end{array}$ & $\begin{array}{c}0.1617^{* * *} \\
(0.0096)\end{array}$ & $\begin{array}{c}0.1245^{* * *} \\
(0.0071)\end{array}$ & $\begin{array}{c}0.0373^{* * *} \\
(0.0120)\end{array}$ \\
\hline$\alpha_{2}$ & $\begin{array}{c}-0.0134^{* * *} \\
(0.0042)\end{array}$ & $\begin{array}{c}-0.0551^{* * *} \\
(0.0074)\end{array}$ & $\begin{array}{c}0.0001 \\
(0.0049)\end{array}$ & $\begin{array}{c}-0.0552^{* * *} \\
(0.0089)\end{array}$ \\
\hline$\alpha_{3}$ & $\begin{array}{c}0.0353^{* * *} \\
(0.0027)\end{array}$ & $\begin{array}{c}0.0270^{* * *} \\
(0.0051)\end{array}$ & $\begin{array}{c}0.0291^{* * *} \\
(0.0029)\end{array}$ & $\begin{array}{l}-0.0022 \\
(0.0059)\end{array}$ \\
\hline \multicolumn{5}{|l|}{ Mother education } \\
\hline$\overline{\alpha .1}$ & $\begin{array}{c}0.1100^{* * *} \\
(0.0071)\end{array}$ & $\begin{array}{c}0.0825^{* * *} \\
(0.0115)\end{array}$ & $\begin{array}{c}0.1202^{* * * *} \\
(0.0088)\end{array}$ & $\begin{array}{c}-0.0377^{* * *} \\
(0.0145)\end{array}$ \\
\hline$\alpha_{.2}$ & $\begin{array}{c}0.0241^{* * *} \\
(0.0043)\end{array}$ & $\begin{array}{l}-0.0026 \\
(0.0075)\end{array}$ & $\begin{array}{c}0.0322^{* * *} \\
(0.0049)\end{array}$ & $\begin{array}{c}-0.0348^{* * *} \\
(0.0089)\end{array}$ \\
\hline$\alpha .3$ & $\begin{array}{c}0.0192^{* * *} \\
(0.0027)\end{array}$ & $\begin{array}{c}0.0057 \\
(0.0052)\end{array}$ & $\begin{array}{c}0.0218^{* * * *} \\
(0.0029)\end{array}$ & $\begin{array}{c}-0.0161^{* * *} \\
(0.0060)\end{array}$ \\
\hline$\alpha_{1 .}-\alpha_{2}$ & $\begin{array}{c}0.1669^{* * *} \\
(0.0056)\end{array}$ & $\begin{array}{c}0.2169^{* * * *} \\
(0.0087)\end{array}$ & $\begin{array}{c}0.1244^{* * *} \\
(0.0069)\end{array}$ & $\begin{array}{c}0.0925^{* * *} \\
(0.0111)\end{array}$ \\
\hline$\alpha_{.1}-\alpha_{.2}$ & $\begin{array}{c}0.0859^{* * *} \\
(0.0093)\end{array}$ & $\begin{array}{c}0.0851^{* * *} \\
(0.0146)\end{array}$ & $\begin{array}{c}0.0880^{* * *} \\
(0.0117)\end{array}$ & $\begin{array}{l}-0.0030 \\
(0.0187)\end{array}$ \\
\hline$\left(\alpha_{1 .}-\alpha_{2 .}\right)-\left(\alpha_{.1}-\alpha_{.2}\right)$ & $\begin{array}{c}0.0809^{* * *} \\
(0.0093)\end{array}$ & $\begin{array}{c}0.1318^{* * *} \\
(0.0146)\end{array}$ & $\begin{array}{c}0.0363^{* * *} \\
(0.0117)\end{array}$ & $\begin{array}{c}0.0954^{* * *} \\
(0.0187)\end{array}$ \\
\hline
\end{tabular}

Notes: Source: Almalaurea XIX Profilo dei Laureati survey (2017 cohort of graduates). Sample: 159,610 students who graduated from high school and from university in Italy, from 3-years and 5-years degree cycles with non-missing value of all covariates included in the analysis. Columns (1)(3) present different sets of OLS estimates of equation (1) in the paper, reported here for convenience $S T E M_{i 2}=\alpha_{0}+\alpha_{1} . F E d u_{1} .+\alpha_{2} . F E d u_{2} .+$ $\alpha_{3 .} F E d u_{3 .}+\alpha_{.1} M E d u_{.1}+\alpha_{.2} M E d u_{.2}+\alpha_{.3} M E d u_{.3}+\alpha_{X}^{\prime} X_{i}+\varepsilon_{i 2}$, where $S T E M_{i 2}$ denotes a dummy taking the value 1 if student $i$ graduates from a STEM field at university and 0 otherwise; $F E d u_{i .}, M E d u_{. j} i, j \in\{1,2,3,4\}$ are dummy variables denoting the qualification level of fathers and mothers respectively, where $i=1(j=1)$ if the father (mother) has STEM-degree qualification, $i=2(j=2)$ if the father (mother) has a non-STEM degree qualification, $i=3(j=3)$ if the father (mother) has a high school qualification and $i=4(j=4)$ if the father (mother) has a junior high school (JHS) qualification or less. $X$ includes the following covariates: a dummy for the region of residence in the south, a set of dummies denoting the social class that distinguish between upper class, middle class and lowerclass (the reference category), a set of dummies denoting fathers' and mothers' professions that distinguish between self-employed workers, entrepreneurs, liberal professionals, managers, teachers, white collars, stay-at-home and blue collars (the reference category). Column (1) uses data for all students. Column (2) and (3) use data on male and female students only, respectively. Estimates of column (4) correspond to interaction terms of a fully interacted model specification by student gender. Robust standard errors in parentheses. * significant at $10 \%$; ** significant at $5 \%,{ }^{* *}$ significant at $1 \%$ or better. 
Table 4: Estimates of the effects of parental education on the attainment of a STEM degree at the university, pooled and by gender of the student.

\begin{tabular}{|c|c|c|c|c|}
\hline & $\begin{array}{c}\text { Pooled } \\
(1) \\
\text { (mean: } 0.228)\end{array}$ & $\begin{array}{c}\text { Males } \\
(2) \\
\text { (mean: } 0.341)\end{array}$ & $\begin{array}{c}\text { Females } \\
(3) \\
\text { (mean: } 0.155)\end{array}$ & $\begin{array}{c}\text { Males-Females } \\
\text { (4) }\end{array}$ \\
\hline & \multicolumn{4}{|c|}{ Both parents with with degree in STEM } \\
\hline$\beta_{11}$ & $\begin{array}{c}0.2589^{* * *} \\
(0.0121)\end{array}$ & $\begin{array}{c}0.2371^{* * *} \\
(0.0184)\end{array}$ & $\begin{array}{c}0.2445^{* * *} \\
(0.0157)\end{array}$ & $\begin{array}{c}-0.0074 \\
(0.0242)\end{array}$ \\
\hline & \multicolumn{4}{|c|}{ Father with degree in STEM different mother education levels } \\
\hline$\beta_{12}$ & $\begin{array}{c}0.1720^{* * *} \\
(0.0089)\end{array}$ & $\begin{array}{c}0.1600^{* * *} \\
(0.0142)\end{array}$ & $\begin{array}{c}0.1474^{* * *} \\
(0.0108)\end{array}$ & $\begin{array}{c}0.0126 \\
(0.0179)\end{array}$ \\
\hline$\beta_{13}$ & $\begin{array}{c}0.1802^{* * *} \\
(0.0084)\end{array}$ & $\begin{array}{c}0.1737^{* * *} \\
(0.0136)\end{array}$ & $\begin{array}{c}0.1543^{* * *} \\
(0.0101)\end{array}$ & $\begin{array}{c}0.0194 \\
(0.0169)\end{array}$ \\
\hline$\beta_{14}$ & $\begin{array}{c}0.1719^{* * *} \\
(0.0216)\end{array}$ & $\begin{array}{c}0.1584^{* * *} \\
(0.0343)\end{array}$ & $\begin{array}{c}0.1526^{* * *} \\
(0.0265)\end{array}$ & $\begin{array}{c}0.0058 \\
(0.0433)\end{array}$ \\
\hline & \multicolumn{4}{|c|}{ Mother with degree in STEM different father education levels } \\
\hline$\beta_{21}$ & $\begin{array}{c}0.0766^{* * *} \\
(0.0111)\end{array}$ & $\begin{array}{c}0.0158 \\
(0.0178)\end{array}$ & $\begin{array}{c}0.0961^{* * *} \\
(0.0139)\end{array}$ & $\begin{array}{c}-0.0803^{* * *} \\
(0.0226)\end{array}$ \\
\hline$\beta_{31}$ & $\begin{array}{c}0.1682^{* * *} \\
(0.0116)\end{array}$ & $\begin{array}{c}0.1308^{* * *} \\
(0.0188)\end{array}$ & $\begin{array}{c}0.1718^{* * *} \\
(0.0143)\end{array}$ & $\begin{array}{c}-0.0410^{*} \\
(0.0236)\end{array}$ \\
\hline$\beta_{41}$ & $\begin{array}{c}0.1329^{* * *} \\
(0.0260)\end{array}$ & $\begin{array}{c}0.0975^{* *} \\
(0.0436)\end{array}$ & $\begin{array}{c}0.1397^{* * *} \\
(0.0313)\end{array}$ & $\begin{array}{l}-0.0422 \\
(0.0537)\end{array}$ \\
\hline
\end{tabular}

Notes: Source: Almalaurea XIX Profilo dei Laureati survey (2017 cohort of graduates). Sample: 159,610 students who graduated from high school and from university in Italy, from 3-years and 5-years degree cycles with non-missing value of all covariates included in the analysis. Columns (1)-(3) present different sets of OLS estimates of equation (3) in the paper on the pooled sample, on the sample of male students and on the sample of females students, respectively. The outcome is $S T E M_{i 2}$ a dummy taking the value 1 if student $i$ graduates from a STEM field at university and 0 otherwise. All equations include $X$, the following set of covariates: a dummy for the region of residence in the south, a set of dummies denoting the social class that distinguish between upper class, middle class and lowerclass (the reference category), a set of dummies denoting fathers' and mothers' professions that distinguish between self-employed workers, entrepreneurs, liberal professionals, managers, teachers, white collars, stay-at-home and blue collars (the reference category). Estimates of column (4) correspond to interaction terms of a fully interacted model specification by student gender. $\beta_{i j} i, j i n\{1,2,3,4\}$ denote the differential effect of having a father with qualification $i$ and a mother with qualification $j$ on the probability of completing a STEM university degree, respectively, with respect to the case in which both parents hold a qualification equal or lower to a junior high school degree. Robust standard errors in parentheses. ${ }^{*}$ significant at $10 \% ; * *$ significant at $5 \%, * * *$ significant at $1 \%$ or better. 
Table 5: Estimates of the effects of parental education on the attainment of a STEM degree at high school, pooled and by gender of the student.

\begin{tabular}{|c|c|c|c|c|}
\hline & $\begin{array}{c}\text { Pooled } \\
(1) \\
\text { (mean: } 0.515)\end{array}$ & $\begin{array}{c}\text { Males } \\
(2) \\
\text { (mean: } 0.698)\end{array}$ & $\begin{array}{c}\text { Females } \\
(3) \\
\text { (mean: } 0.397)\end{array}$ & $\begin{array}{c}\text { Males-Females } \\
\text { (4) }\end{array}$ \\
\hline \multicolumn{5}{|l|}{ Father education } \\
\hline$\lambda_{1}$ & $\begin{array}{c}0.1260 * * * \\
(0.0063)\end{array}$ & $\begin{array}{c}0.0830 * * * \\
(0.0086)\end{array}$ & $\begin{array}{c}0.1251^{* * *} \\
(0.0085)\end{array}$ & $\begin{array}{c}-0.0421^{* * *} \\
(0.0121)\end{array}$ \\
\hline$\lambda_{2}$ & $\begin{array}{c}0.0241^{* * *} \\
(0.0052)\end{array}$ & $\begin{array}{c}-0.0133^{*} \\
(0.0074)\end{array}$ & $\begin{array}{c}0.0189^{* * *} \\
(0.0067)\end{array}$ & $\begin{array}{c}-0.0323^{* * *} \\
(0.0100)\end{array}$ \\
\hline$\lambda_{3}$ & $\begin{array}{c}0.0502^{* * *} \\
(0.0033)\end{array}$ & $\begin{array}{c}0.0329^{* * *} \\
(0.0050)\end{array}$ & $\begin{array}{c}0.0429^{* * *} \\
(0.0040)\end{array}$ & $\begin{array}{l}-0.0099 \\
(0.0064)\end{array}$ \\
\hline \multicolumn{5}{|l|}{ Mother education } \\
\hline$\lambda_{.1}$ & $\begin{array}{c}0.1229 * * * \\
(0.0076)\end{array}$ & $\begin{array}{c}0.0622^{* * *} \\
(0.0103)\end{array}$ & $\begin{array}{c}0.1557^{* * *} \\
(0.0103)\end{array}$ & $\begin{array}{c}-0.0935^{* * *} \\
(0.0146)\end{array}$ \\
\hline$\lambda_{.2}$ & $\begin{array}{c}0.0222^{* * *} \\
(0.0051)\end{array}$ & $\begin{array}{l}-0.0109 \\
(0.0073)\end{array}$ & $\begin{array}{c}0.0304^{* * *} \\
(0.0065)\end{array}$ & $\begin{array}{c}-0.0413^{* * *} \\
(0.0098)\end{array}$ \\
\hline$\lambda_{.3}$ & $\begin{array}{c}0.0301^{* * *} \\
(0.0033)\end{array}$ & $\begin{array}{c}0.0221^{* * *} \\
(0.0051)\end{array}$ & $\begin{array}{c}0.0269^{* * *} \\
(0.0041)\end{array}$ & $\begin{array}{l}-0.0048 \\
(0.0065)\end{array}$ \\
\hline$\lambda_{1}-\lambda_{2}$ & $\begin{array}{c}0.1018^{* * *} \\
(0.0059)\end{array}$ & $\begin{array}{c}0.0963^{* * *} \\
(0.0079)\end{array}$ & $\begin{array}{c}0.1062^{* * *} \\
(0.0082)\end{array}$ & $\begin{array}{l}-0.0098 \\
(0.0114)\end{array}$ \\
\hline$\lambda_{.1}-\lambda_{.2}$ & $\begin{array}{c}0.1008^{* * *} \\
(0.0071)\end{array}$ & $\begin{array}{c}0.0731^{* * *} \\
(0.0095)\end{array}$ & $\begin{array}{c}0.1253^{* * *} \\
(0.0098)\end{array}$ & $\begin{array}{c}-0.0521^{* * *} \\
(0.0137)\end{array}$ \\
\hline$\left(\lambda_{1 .}-\lambda_{2 .}\right)-\left(\lambda_{.1}-\lambda_{.2}\right)$ & $\begin{array}{c}0.0010 \\
(0.0098)\end{array}$ & $\begin{array}{c}0.0232^{*} \\
(0.0130)\end{array}$ & $\begin{array}{l}-0.0191 \\
(0.0136)\end{array}$ & $\begin{array}{c}0.0423^{* *} \\
(0.0189)\end{array}$ \\
\hline
\end{tabular}

Notes: Source: Almalaurea XIX Profilo dei Laureati survey (2017 cohort of graduates). Sample: 159,610 students who graduated from high school and from university in Italy, from 3-years and 5-years degree cycles with non-missing value of all covariates included in the analysis. Columns (1)-(3) present different sets of OLS estimates of equation (2) in the paper, reported here for convenience $S T E M_{i 1}=\lambda_{0}+\lambda_{1 .} F E d u_{1}+\lambda_{2 .} F E d u_{2 .}+\lambda_{3 .} F E d u_{3 .}+\lambda_{.1} M E d u_{.1}+\lambda_{.2} M E d u_{.2}+\lambda_{.3} M E d u_{.3}+\lambda_{X}^{\prime} X_{i}+\varepsilon_{i 1}$, where $S T E M_{i 1}$ denotes a dummy taking the value 1 if student $i$ completes a STEM field high school degree and 0 otherwise; $F E d u_{i .}, M E d u_{. j} i, j \in\{1,2,3,4\}$ are dummy variables denoting the qualification level of fathers and mothers respectively, where $i=1(j=1)$ if the father (mother) has STEM-degree qualification, $i=2(j=2)$ if the father (mother) has a non-STEM degree qualification, $i=3(j=3)$ if the father (mother) has a high school qualification and $i=4(j=4)$ if the father (mother) has a junior high school (JHS) qualification or less. $X$ includes the following covariates: a dummy for the region of residence in the south, a set of dummies denoting the social class that distinguish between upper class, middle class and lowerclass (the reference category), a set of dummies denoting fathers' and mothers' professions that distinguish between self-employed workers, entrepreneurs, liberal professionals, managers, teachers, white collars, stay-at-home and blue collars (the reference category). Column (1) uses data for all students. Column (2) and (3) use data on male and female students only, respectively. Estimates of column (4) correspond to interaction terms of a fully interacted model specification by student gender. Robust standard errors in parentheses. ${ }^{*}$ significant at $10 \%$; ** significant at $5 \%, * * *$ significant at $1 \%$ or better. 
Table 6: Estimates of the effects of parental education on the attainment of a STEM degree at high school, pooled and by gender of the student.

\begin{tabular}{|c|c|c|c|c|}
\hline & $\begin{array}{c}\text { Pooled } \\
(1) \\
\text { (mean: } 0.515)\end{array}$ & $\begin{array}{c}\text { Males } \\
(2) \\
\text { (mean: } 0.698)\end{array}$ & $\begin{array}{c}\text { Females } \\
(3) \\
\text { (mean: } 0.397)\end{array}$ & $\begin{array}{c}\text { Males-Females } \\
\text { (4) }\end{array}$ \\
\hline$\psi_{11}$ & $\begin{array}{c}0.2178^{* * *} \\
(0.0118)\end{array}$ & $\begin{array}{c}\text { parents with } \\
0.1022^{* * *} \\
(0.0161)\end{array}$ & $\begin{array}{c}\text { th degree in } \\
0.2662^{* * *} \\
(0.0165)\end{array}$ & $\begin{array}{l}-0.1640^{* * *} \\
\quad(0.0231)\end{array}$ \\
\hline$\psi_{12}$ & $\begin{array}{c}\text { Father with } \\
0.1288^{* * *} \\
(0.0095)\end{array}$ & $\begin{array}{c}\text { ree in STEM } \\
0.0641^{* * *} \\
(0.0131)\end{array}$ & $\begin{array}{c}\text { ferent mother } \\
0.1306^{* * *} \\
(0.0128)\end{array}$ & $\begin{array}{c}\text { ucation levels } \\
-0.0665^{* * *} \\
(0.0183)\end{array}$ \\
\hline$\psi_{13}$ & $\begin{array}{c}0.1931^{* * *} \\
(0.0087)\end{array}$ & $\begin{array}{c}0.1369^{* * *} \\
(0.0116)\end{array}$ & $\begin{array}{c}0.1903^{* * *} \\
(0.0119)\end{array}$ & $\begin{array}{c}-0.0533^{* * *} \\
(0.0166)\end{array}$ \\
\hline$\psi_{14}$ & $\begin{array}{c}0.2024^{* * *} \\
(0.0216)\end{array}$ & $\begin{array}{c}0.1784^{* * *} \\
(0.0257)\end{array}$ & $\begin{array}{c}0.1742^{* * *} \\
(0.0302)\end{array}$ & $\begin{array}{c}0.0043 \\
(0.0396)\end{array}$ \\
\hline$\psi_{21}$ & $\begin{array}{c}\text { Mother with } \\
0.1390^{* * *} \\
(0.0126)\end{array}$ & $\begin{array}{c}\text { gree in STEM } \\
0.0569^{* * *} \\
(0.0173)\end{array}$ & $\begin{array}{c}\text { ffferent father } \\
0.1568^{* * *} \\
(0.0174)\end{array}$ & $\begin{array}{c}\text { ucation levels } \\
-0.1000^{* * *} \\
(0.0245)\end{array}$ \\
\hline$\psi_{31}$ & $\begin{array}{c}0.2196^{* * *} \\
(0.0116)\end{array}$ & $\begin{array}{c}0.1471^{* * *} \\
(0.0153)\end{array}$ & $\begin{array}{c}0.2372^{* * *} \\
(0.0161)\end{array}$ & $\begin{array}{c}-0.0902^{* * *} \\
(0.0222)\end{array}$ \\
\hline$\psi_{41}$ & $\begin{array}{c}0.1803^{* * *} \\
(0.0269)\end{array}$ & $\begin{array}{c}0.0968^{* * *} \\
(0.0372)\end{array}$ & $\begin{array}{c}0.2103^{* * *} \\
(0.0360)\end{array}$ & $\begin{array}{c}-0.1135^{* *} \\
(0.0518)\end{array}$ \\
\hline
\end{tabular}

Notes: Source: Almalaurea XIX Profilo dei Laureati survey (2017 cohort of graduates). Sample: 155,603 students who graduated from high school and from university in Italy, from 3-years and 5-years degree cycles with non-missing value of all covariates included in the analysis. Columns (1)-(3) present different sets of OLS estimates of equation (4) in the paper on the pooled sample, on the sample of male students and on the sample of females students, respectively. The outcome is $S T E M_{i 1}$ a dummy taking the value 1 if student $i$ graduates from a STEM field at high school and 0 otherwise. All equations include $X$, the following set of covariates: a dummy for the region of residence in the south, a set of dummies denoting the social class that distinguish between upper class, middle class and lowerclass (the reference category), a set of dummies denoting fathers' and mothers' professions that distinguish between self-employed workers, entrepreneurs, liberal professionals, managers, teachers, white collars, stay-at-home and blue collars (the reference category). Estimates of column (4) correspond to interaction terms of a fully interacted model specification by student gender. $\psi_{i j} i, j i n\{1,2,3,4\}$ denote the differential effect of having a father with qualification $i$ and a mother with qualification $j$ on the probability of completing a STEM high-school degree, respectively, with respect to the case in which both parents hold a qualification equal or lower to a junior high school degree. Robust standard errors in parentheses. ${ }^{*}$ significant at $10 \% ;{ }^{* *}$ significant at $5 \%,{ }^{* * *}$ significant at $1 \%$ or better. 
Table 7: Differential effects of parental education on the attainment of a STEM degree at the university wrt to the same attainment at High School, pooled and by gender of the student. Fixed effects (FE) estimates.

\begin{tabular}{|c|c|c|c|c|}
\hline & $\begin{array}{c}\text { Pooled } \\
\text { (1) }\end{array}$ & $\begin{array}{l}\text { Males } \\
(2)\end{array}$ & $\begin{array}{c}\text { Females } \\
(3)\end{array}$ & $\begin{array}{c}\text { Males-Females } \\
\text { (4) }\end{array}$ \\
\hline \multicolumn{5}{|l|}{ Father education } \\
\hline$\overline{\Delta \gamma_{1}}$ & $\begin{array}{c}0.0275^{* * *} \\
(0.0073)\end{array}$ & $\begin{array}{c}0.0788^{* * *} \\
(0.0112)\end{array}$ & $\begin{array}{l}-0.0006 \\
(0.0098)\end{array}$ & $\begin{array}{c}0.0794^{* * *} \\
(0.0149)\end{array}$ \\
\hline$\Delta \gamma_{2}$ & $\begin{array}{c}-0.0376^{* * *} \\
(0.0057)\end{array}$ & $\begin{array}{c}-0.0418^{* * *} \\
(0.0091)\end{array}$ & $\begin{array}{c}-0.0189 * * \\
(0.0074)\end{array}$ & $\begin{array}{c}-0.0229^{*} \\
(0.0117)\end{array}$ \\
\hline$\Delta \gamma_{3}$ & $\begin{array}{c}-0.0149^{* * *} \\
(0.0035)\end{array}$ & $\begin{array}{l}-0.0060 \\
(0.0060)\end{array}$ & $\begin{array}{c}-0.0137^{* * *} \\
(0.0043)\end{array}$ & $\begin{array}{c}0.0078 \\
(0.0074)\end{array}$ \\
\hline \multicolumn{5}{|l|}{ Mother education } \\
\hline$\Delta \gamma_{.1}$ & $\begin{array}{l}-0.0129 \\
(0.0089)\end{array}$ & $\begin{array}{c}0.0203 \\
(0.0133)\end{array}$ & $\begin{array}{c}-0.0354^{* * * *} \\
(0.0121)\end{array}$ & $\begin{array}{c}0.0557^{* * *} \\
(0.0180)\end{array}$ \\
\hline$\Delta \gamma_{.2}$ & $\begin{array}{c}0.0019 \\
(0.0057)\end{array}$ & $\begin{array}{c}0.0083 \\
(0.0089)\end{array}$ & $\begin{array}{c}0.0018 \\
(0.0073)\end{array}$ & $\begin{array}{c}0.0065 \\
(0.0115)\end{array}$ \\
\hline$\Delta \gamma_{.3}$ & $\begin{array}{c}-0.0110^{* * *} \\
(0.0036)\end{array}$ & $\begin{array}{c}-0.0164^{* * *} \\
(0.0061)\end{array}$ & $\begin{array}{l}-0.0051 \\
(0.0044)\end{array}$ & $\begin{array}{l}-0.0113 \\
(0.0075)\end{array}$ \\
\hline$\Delta \gamma_{1}-\Delta \gamma_{2}$ & $\begin{array}{c}0.0651^{* * *} \\
(0.0070)\end{array}$ & $\begin{array}{c}0.1205^{* * *} \\
(0.0104)\end{array}$ & $\begin{array}{l}0.0182^{*} \\
(0.0095)\end{array}$ & $\begin{array}{c}0.1023^{* * *} \\
(0.0141)\end{array}$ \\
\hline$\Delta \gamma_{.1}-\Delta \gamma_{.2}$ & $\begin{array}{c}-0.0148^{*} \\
(0.0085)\end{array}$ & $\begin{array}{c}0.0120 \\
(0.0124)\end{array}$ & $\begin{array}{c}-0.0372^{* * *} \\
(0.0117)\end{array}$ & $\begin{array}{c}0.0492^{* * *} \\
(0.0170)\end{array}$ \\
\hline$\left(\Delta \gamma_{1 .}-\Delta \gamma_{2 .}\right)-\left(\Delta \gamma_{.1}-\Delta \gamma_{.2}\right)$ & $\begin{array}{c}0.0799^{* * * *} \\
(0.0117) \\
\end{array}$ & $\begin{array}{c}0.1086^{* * *} \\
(0.0172) \\
\end{array}$ & $\begin{array}{c}0.0554^{* * *} \\
(0.0159) \\
\end{array}$ & $\begin{array}{c}0.0531^{* *} \\
(0.0234) \\
\end{array}$ \\
\hline
\end{tabular}

Notes: Source: Almalaurea XIX Profilo dei Laureati survey (2017 cohort of graduates). Sample: 159,610 students who graduated from high school and from university in Italy, from 3-years and 5-years degree cycles with non-missing value of all covariates included in the analysis. Columns (1)-(3) present different sets of FE estimates of equation (1) in the paper. The outcome where $S T E M_{i 2}$ denotes a dummy taking the value 1 if student $i$ completes a STEM field university degree and 0 otherwise. $X$ includes the following covariates: a dummy for the region of residence in the south, a set of dummies denoting the social class that distinguish between upper class, middle class and lowerclass (the reference category), a set of dummies denoting fathers' and mothers' professions that distinguish between self-employed workers, entrepreneurs, liberal professionals, managers, teachers, white collars, stay-at-home and blue collars (the reference category). The notation used in the table reflects the formulation presented in equation (5) in the paper. Column (1) uses data for all students. Column (2) and (3) use data on male and female students only, respectively. Estimates of column (4) correspond to interaction terms of a fully interacted model specification by student gender. Robust standard errors in parentheses. ${ }^{*}$ significant at $10 \%$; ${ }^{* *}$ significant at $5 \%, * * *$ significant at $1 \%$ or better. 
Table 8: Differential effects of parental education on the attainment of a STEM degree at the university wrt to the same attainment at High School, pooled and by gender of the student.Fixed effects (FE) estimates.

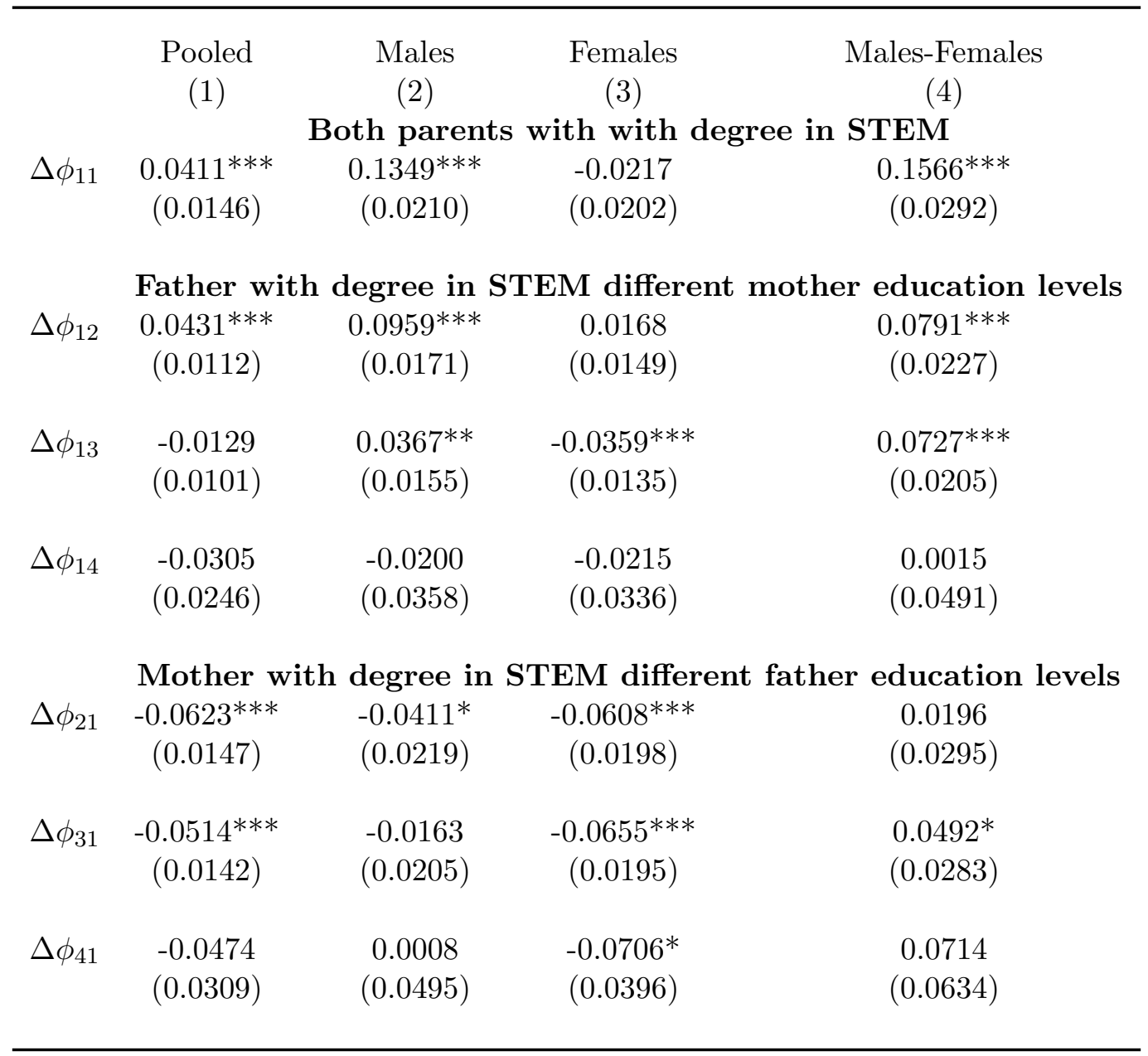

Notes: Source: Almalaurea XIX Profilo dei Laureati survey (2017 cohort of graduates). Sample: 159,610 students who graduated from high school and from university in Italy, from 3-years and 5-years degree cycles with non-missing value of all covariates included in the analysis. Columns (1)-(3) present different sets of FE estimates of equation (3) in the paper on the pooled sample, on the sample of male students and on the sample of females students, respectively. The outcome is $S T E M_{i 2}$ a dummy taking the value 1 if student $i$ graduates from a STEM field at university and 0 otherwise. All equations include $X$, the following set of covariates: a dummy for the region of residence in the south, a set of dummies denoting the social class that distinguish between upper class, middle class and lowerclass (the reference category), a set of dummies denoting fathers' and mothers' professions that distinguish between self-employed workers, entrepreneurs, liberal professionals, managers, teachers, white collars, stay-at-home and blue collars (the reference category). The notation used in the table mimics the one used in the formulation of the baseline case presented in equation (5) in the paper. Estimates of column (4) correspond to interaction terms of a fully interacted model specification by student gender. Robust standard errors in parentheses. * significant at $10 \%$; ** significant at $5 \%,{ }^{* * *}$ significant at $1 \%$ or better. 
Table 9: Estimates of the effects of parental education on the attainment of a STEM degree at the university, pooled and by gender of the student, controlling for field choice in High School (HS).

\begin{tabular}{|c|c|c|c|c|}
\hline & $\begin{array}{c}\text { Pooled } \\
(1) \\
\text { (mean: } 0.228)\end{array}$ & $\begin{array}{c}\text { Males } \\
(2) \\
\text { (mean: } 0.341)\end{array}$ & $\begin{array}{c}\text { Females } \\
(3) \\
\text { (mean: } 0.155)\end{array}$ & $\begin{array}{c}\text { Males-Females } \\
(4)\end{array}$ \\
\hline \multicolumn{5}{|l|}{ STEM choice in HS } \\
\hline$\delta_{H S \_s t e m}$ & $\begin{array}{c}0.2455^{* * *} \\
(0.0020)\end{array}$ & $\begin{array}{c}0.2763^{* * *} \\
(0.0035)\end{array}$ & $\begin{array}{c}0.1710^{* * *} \\
(0.0025)\end{array}$ & $\begin{array}{c}0.1054^{* * *} \\
(0.0043)\end{array}$ \\
\hline \multicolumn{5}{|l|}{ Father education } \\
\hline$\overline{\delta_{1}}$ & $\begin{array}{c}0.1225^{* * *} \\
(0.0057)\end{array}$ & $\begin{array}{c}0.1388^{* * *} \\
(0.0094)\end{array}$ & $\begin{array}{c}0.1031^{* * *} \\
(0.0070)\end{array}$ & $\begin{array}{c}0.0357^{* * *} \\
(0.0117)\end{array}$ \\
\hline$\delta_{2}$ & $\begin{array}{c}-0.0194^{* * *} \\
(0.0041)\end{array}$ & $\begin{array}{c}-0.0514^{* * *} \\
(0.0072)\end{array}$ & $\begin{array}{l}-0.0032 \\
(0.0048)\end{array}$ & $\begin{array}{c}-0.0483^{* * *} \\
(0.0086)\end{array}$ \\
\hline$\delta_{3}$ & $\begin{array}{c}0.0230 * * * \\
(0.0026)\end{array}$ & $\begin{array}{c}0.0179^{* * *} \\
(0.0049)\end{array}$ & $\begin{array}{c}0.0218^{* * *} \\
(0.0028)\end{array}$ & $\begin{array}{l}-0.0039 \\
(0.0057)\end{array}$ \\
\hline \multicolumn{5}{|l|}{ Mother education } \\
\hline$\overline{\delta_{.1}}$ & $\begin{array}{c}0.0798^{* * * *} \\
(0.0069)\end{array}$ & $\begin{array}{c}0.0653^{* * *} \\
(0.0111)\end{array}$ & $\begin{array}{c}0.0936^{* * *} \\
(0.0086)\end{array}$ & $\begin{array}{c}-0.0283^{* *} \\
(0.0141)\end{array}$ \\
\hline$\delta_{.2}$ & $\begin{array}{c}0.0186^{* * * *} \\
(0.0041)\end{array}$ & $\begin{array}{c}0.0005 \\
(0.0072)\end{array}$ & $\begin{array}{c}0.0270^{* * *} \\
(0.0048)\end{array}$ & $\begin{array}{c}-0.0266^{* * *} \\
(0.0086)\end{array}$ \\
\hline$\delta_{.3}$ & $\begin{array}{c}0.0118^{* * *} \\
(0.0026)\end{array}$ & $\begin{array}{l}-0.0004 \\
(0.0050)\end{array}$ & $\begin{array}{c}0.0172^{* * *} \\
(0.0028)\end{array}$ & $\begin{array}{c}-0.0176^{* * *} \\
(0.0057)\end{array}$ \\
\hline$\delta_{1}-\delta_{2}$ & $\begin{array}{c}0.1419^{* * * *} \\
(0.0054)\end{array}$ & $\begin{array}{c}0.1902^{* * *} \\
(0.0085)\end{array}$ & $\begin{array}{c}0.1062^{* * *} \\
(0.0068)\end{array}$ & $\begin{array}{c}0.0840^{* * *} \\
(0.0109)\end{array}$ \\
\hline$\delta_{.1}-\delta_{.2}$ & $\begin{array}{c}0.0612^{* * *} \\
(0.0066)\end{array}$ & $\begin{array}{c}0.0649^{* * *} \\
(0.0103)\end{array}$ & $\begin{array}{c}0.0666^{* * *} \\
(0.0084)\end{array}$ & $\begin{array}{l}-0.0018 \\
(0.0133)\end{array}$ \\
\hline$\left(\delta_{1 .}-\delta_{2 .}\right)-\left(\delta_{.1}-\delta_{.2}\right)$ & $\begin{array}{c}0.0807^{* * *} \\
(0.0090)\end{array}$ & $\begin{array}{c}0.1254^{* * *} \\
(0.0142)\end{array}$ & $\begin{array}{c}0.0396^{* * *} \\
(0.0114)\end{array}$ & $\begin{array}{c}0.0858^{* * *} \\
(0.0182)\end{array}$ \\
\hline
\end{tabular}

Notes: Source: Almalaurea XIX Profilo dei Laureati survey (2017 cohort of graduates). Sample: 159,610 students who graduated from high school and from university in Italy, from 3-years and 5-years degree cycles with non-missing value of all covariates included in the analysis. Columns (1)-(3) present different sets of OLS estimates of equation (7) in the paper. The outcome variable $S T E M_{i 2}$ denotes a dummy taking the value 1 if student $i$ graduates from a STEM field at university and 0 otherwise; $F E d u_{i .}, M E d u_{. j} i, j \in\{1,2,3,4\}$ are dummy variables denoting the qualification level of fathers and mothers respectively, where $i=1(j=1)$ if the father (mother) has STEM-degree qualification, $i=2(j=2)$ if the father (mother) has a non-STEM degree qualification, $i=3(j=3)$ if the father (mother) has a high school qualification and $i=4(j=4)$ if the father (mother) has a junior high school (JHS) qualification or less. $X$ includes the following covariates: a dummy for the region of residence in the south, a set of dummies denoting the social class that distinguish between upper class, middle class and lowerclass (the reference category), a set of dummies denoting fathers' and mothers' professions that distinguish between self-employed workers, entrepreneurs, liberal professionals, managers, teachers, white collars, stay-at-home and blue collars (the reference category). Column (1) uses data for all students. Column (2) and (3) use data on male and female students only, respectively. Estimates of column (4) correspond to interaction terms of a fully interacted model specification by student gender. Robust standard errors in parentheses. ${ }^{*}$ significant at $10 \%$; $* *$ significant at $5 \%, * * *$ significant at $1 \%$ or better. 
Figure 1: Direct and indirect effects of parental degree on the attainment of a STEM degree at university, pooled.

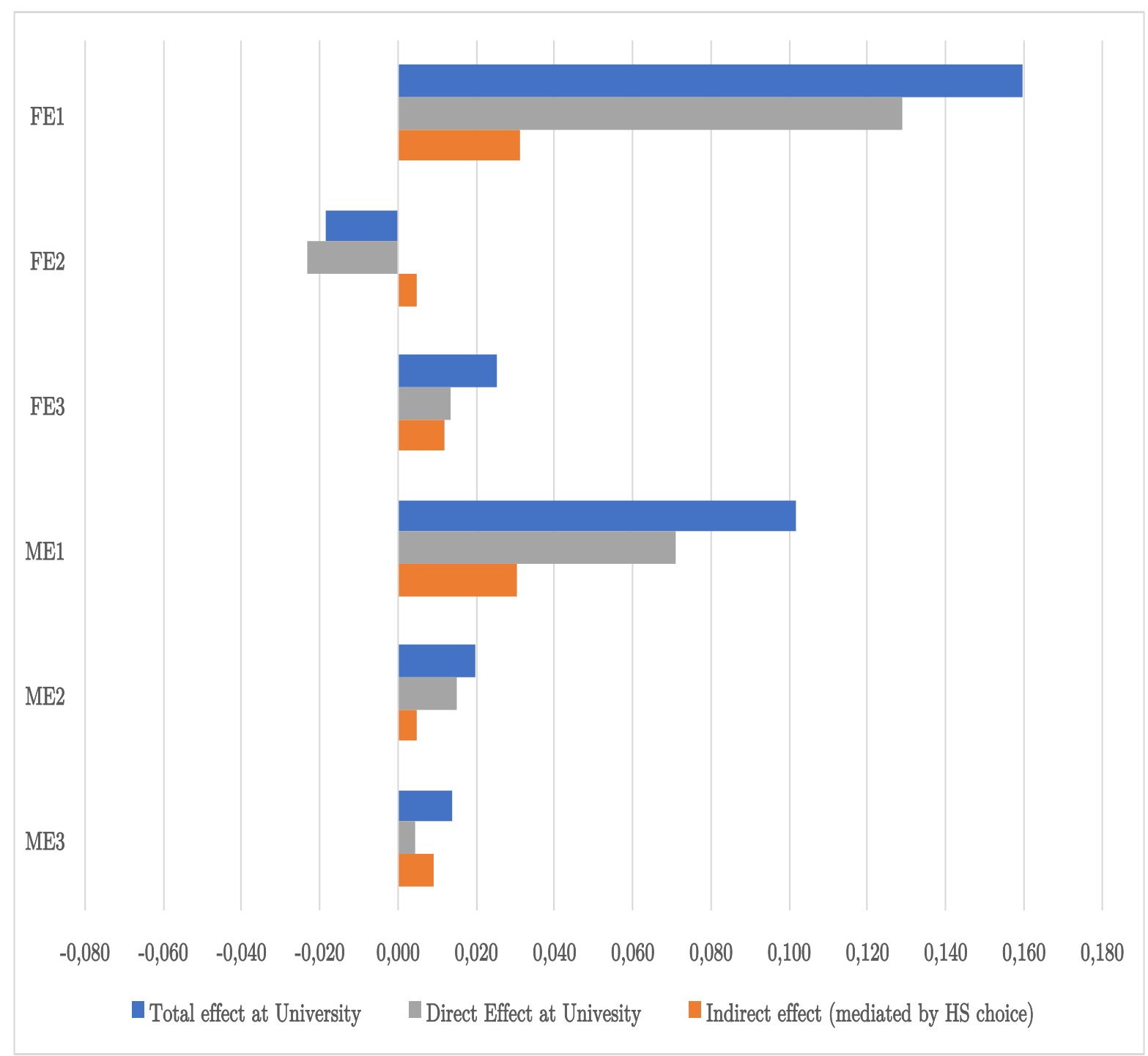

Notes: Source: Almalaurea XIX Profilo dei Laureati survey (2017 cohort of graduates). Sample: 159,610 students who graduated from high school and from university in Italy, from 3-years and 5-years degree cycles with non-missing value of all covariates included in the analysis. The total effect at university presents the estimates of parameters $\alpha_{i}$. and $\alpha_{. j}$ of equation (1) in the paper. The direct effect at university presents the estimates of parameters $\delta_{i}$. and $\delta_{. j}$ of equation (7) in the paper. The indirect effect presents the estimates of parameters $\delta_{H S_{-} s t e m} \lambda_{i}$ and $\delta_{H S_{-} s t e m} \lambda_{. j}$ of equations (7) and (2) in the paper. 
Figure 2: Direct and indirect effects of parental degree on the attainment of a STEM degree at university; males students only.

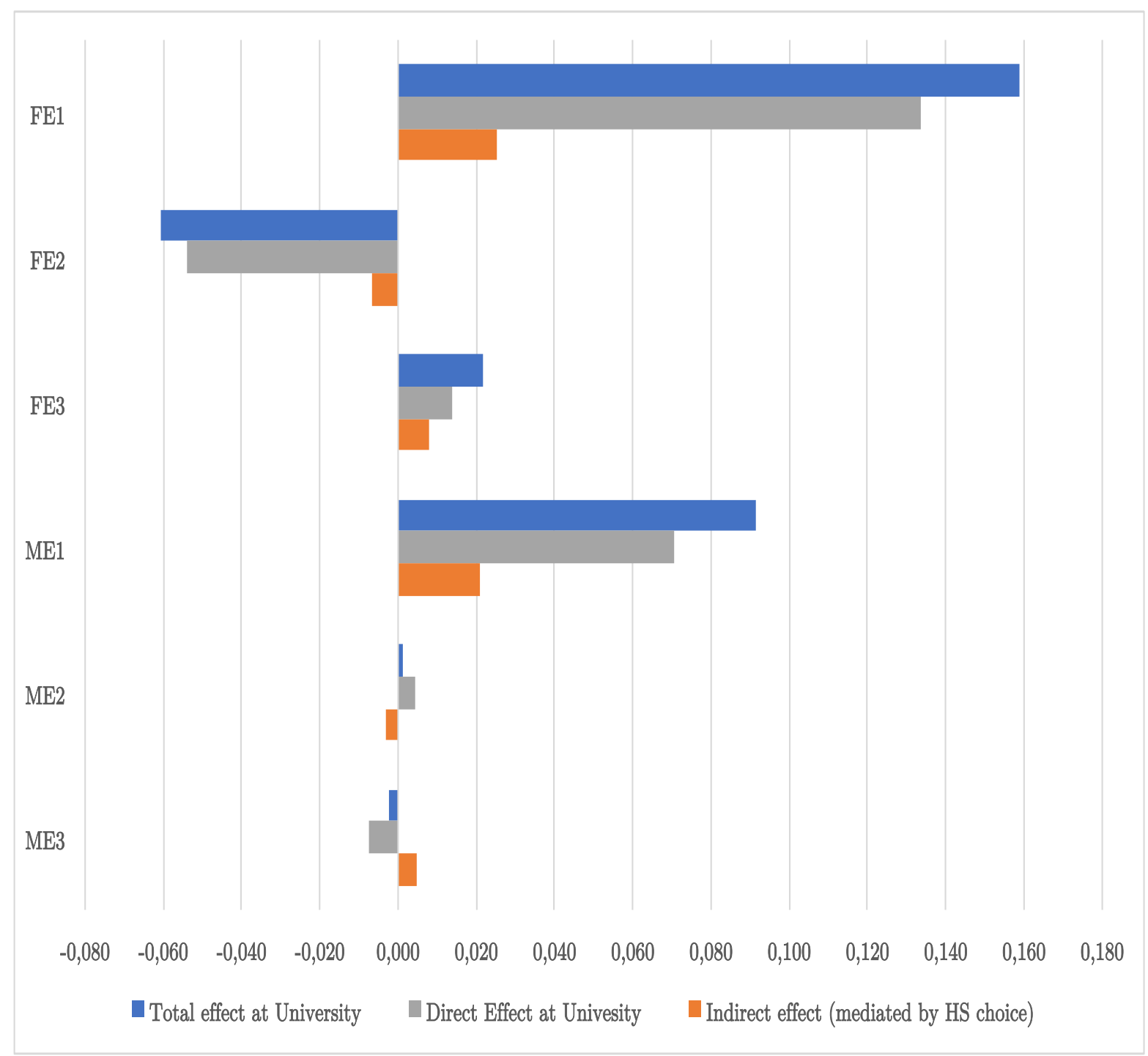

Notes: Source: Almalaurea XIX Profilo dei Laureati survey (2017 cohort of graduates). Sample: 159,610 students who graduated from high school and from university in Italy, from 3-years and 5-years degree cycles with non-missing value of all covariates included in the analysis. The total effect at university presents the estimates of parameters $\alpha_{i}$. and $\alpha_{. j}$ of equation (1) in the paper. The direct effect at university presents the estimates of parameters $\delta_{i}$. and $\delta_{. j}$ of equation (7) in the paper. The indirect effect presents the estimates of parameters $\delta_{H S_{-} s t e m} \lambda_{i}$ and $\delta_{H S_{-} s t e m} \lambda_{. j}$ of equations (7) and (2) in the paper. 
Figure 3: Direct and indirect effects of parental degree on the attainment of a STEM degree at university; female students only.

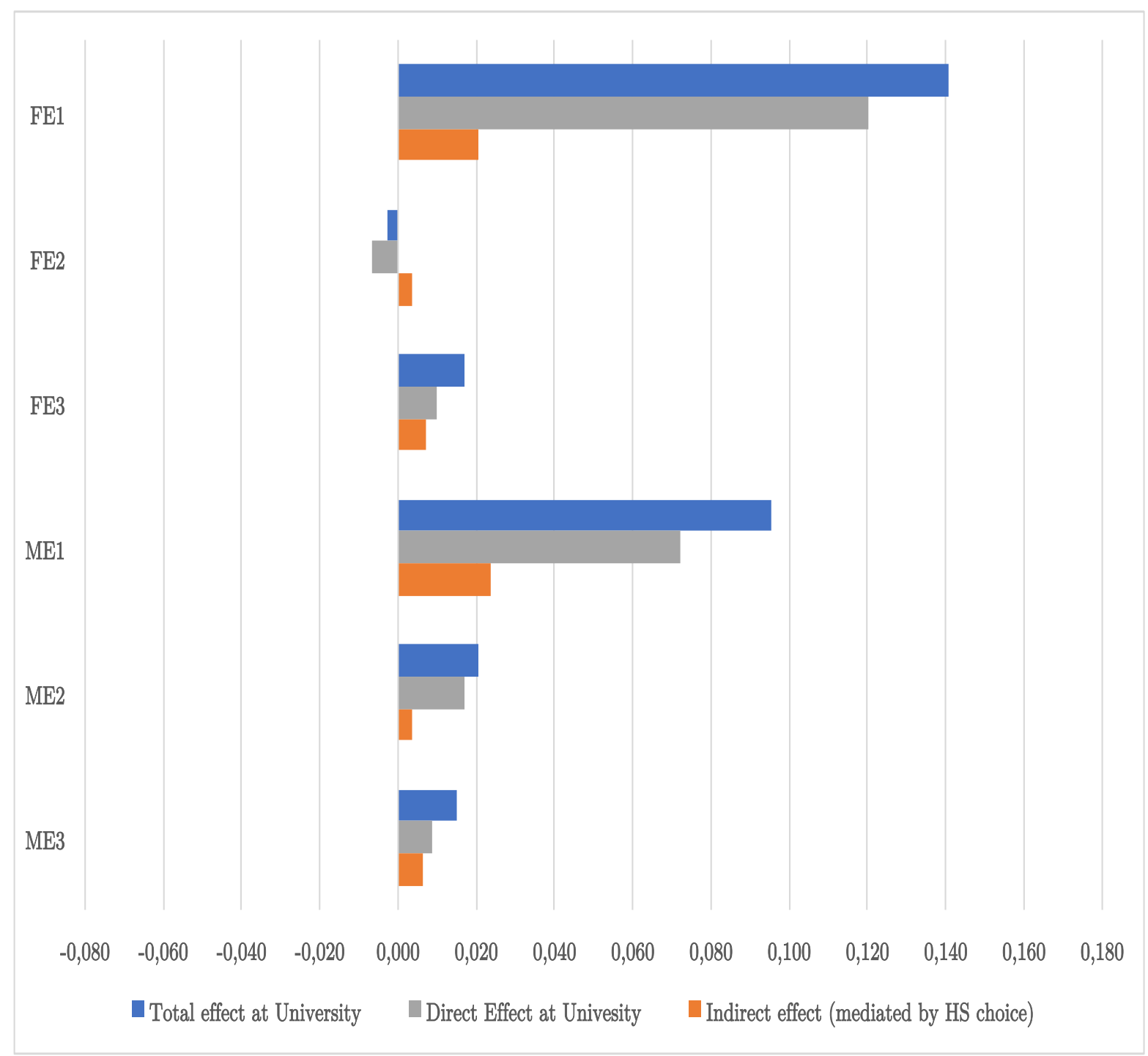

Notes: Source: Almalaurea XIX Profilo dei Laureati survey (2017 cohort of graduates). Sample: 159,610 students who graduated from high school and from university in Italy, from 3-years and 5-years degree cycles with non-missing value of all covariates included in the analysis. The total effect at university presents the estimates of parameters $\alpha_{i}$. and $\alpha_{. j}$ of equation (1) in the paper. The direct effect at university presents the estimates of parameters $\delta_{i}$. and $\delta_{. j}$ of equation (7) in the paper. The indirect effect presents the estimates of parameters $\delta_{H S_{-} s t e m} \lambda_{i}$ and $\delta_{H S_{-} s t e m} \lambda_{. j}$ of equations (7) and (2) in the paper. 
Table 10: Effects of parental education on the attainment of a STEM degree at the university, pooled and by gender of the student.

\begin{tabular}{|c|c|c|c|c|}
\hline & $\begin{array}{l}\text { Pooled } \\
\text { (1) }\end{array}$ & $\begin{array}{c}\text { Males } \\
(2)\end{array}$ & $\begin{array}{c}\text { Females } \\
(3)\end{array}$ & $\begin{array}{c}\text { Males-Females } \\
\text { (4) }\end{array}$ \\
\hline \multicolumn{5}{|c|}{ Father education } \\
\hline$\overline{\alpha_{1}}$ & $\begin{array}{c}0.1406^{* * *} \\
(0.0068)\end{array}$ & $\begin{array}{c}0.1486^{* * *} \\
(0.0110)\end{array}$ & $\begin{array}{c}0.1123^{* * *} \\
(0.0082)\end{array}$ & $\begin{array}{c}0.0363^{* * *} \\
(0.0137)\end{array}$ \\
\hline$\alpha_{2}$ & $\begin{array}{c}0.0059 \\
(0.0049)\end{array}$ & $\begin{array}{c}-0.0283^{* * *} \\
(0.0084)\end{array}$ & $\begin{array}{c}0.0139^{* *} \\
(0.0057)\end{array}$ & $\begin{array}{c}-0.0422^{* * *} \\
(0.0102)\end{array}$ \\
\hline$\alpha_{3}$ & $\begin{array}{c}0.0345^{* * *} \\
(0.0028)\end{array}$ & $\begin{array}{c}0.0261^{* * *} \\
(0.0053)\end{array}$ & $\begin{array}{c}0.0287^{* * *} \\
(0.0030)\end{array}$ & $\begin{array}{l}-0.0026 \\
(0.0061)\end{array}$ \\
\hline \multicolumn{5}{|c|}{ Mother education } \\
\hline$\alpha_{.1}$ & $\begin{array}{c}0.1060^{* * *} \\
(0.0075)\end{array}$ & $\begin{array}{c}0.0797^{* * *} \\
(0.0121)\end{array}$ & $\begin{array}{c}0.1152^{* * *} \\
(0.0092)\end{array}$ & $\begin{array}{c}-0.0355^{* *} \\
(0.0152)\end{array}$ \\
\hline$\alpha_{.2}$ & $\begin{array}{c}0.0271^{* * *} \\
(0.0044)\end{array}$ & $\begin{array}{c}0.0009 \\
(0.0077)\end{array}$ & $\begin{array}{c}0.0342^{* * *} \\
(0.0051)\end{array}$ & $\begin{array}{c}-0.0333^{* * *} \\
(0.0093)\end{array}$ \\
\hline$\alpha_{.3}$ & $\begin{array}{c}0.0199^{* * *} \\
(0.0028)\end{array}$ & $\begin{array}{c}0.0064 \\
(0.0053)\end{array}$ & $\begin{array}{c}0.0222^{* * *} \\
(0.0029)\end{array}$ & $\begin{array}{c}-0.0158^{* * *} \\
(0.0060)\end{array}$ \\
\hline \multicolumn{5}{|c|}{$\begin{array}{l}\text { Interaction terms: } \\
\text { father education } \times \text { liberal professional }\end{array}$} \\
\hline$\overline{\alpha_{L 1}}$ & $\begin{array}{c}0.0346^{* * *} \\
(0.0120)\end{array}$ & $\begin{array}{c}0.0079 \\
(0.0190)\end{array}$ & $\begin{array}{c}0.0397^{* * *} \\
(0.0148)\end{array}$ & $\begin{array}{l}-0.0318 \\
(0.0241)\end{array}$ \\
\hline$\alpha_{L 2}$ & $\begin{array}{c}-0.0571^{* * *} \\
(0.0075)\end{array}$ & $\begin{array}{c}-0.1068^{* * *} \\
(0.0128)\end{array}$ & $\begin{array}{c}-0.0342^{* * *} \\
(0.0087)\end{array}$ & $\begin{array}{c}-0.1068^{* * *} \\
(0.0128)\end{array}$ \\
\hline$\alpha_{L 3}$ & $\begin{array}{c}0.0020 \\
(0.0075)\end{array}$ & $\begin{array}{r}-0.0228^{*} \\
(0.0133)\end{array}$ & $\begin{array}{c}0.0062 \\
(0.0086)\end{array}$ & $\begin{array}{c}-0.0290^{*} \\
(0.0159)\end{array}$ \\
\hline$\alpha_{L 4}$ & $\begin{array}{l}-0.0100 \\
(0.0085)\end{array}$ & $\begin{array}{c}-0.0366^{* *} \\
(0.0168)\end{array}$ & $\begin{array}{l}-0.0004 \\
(0.0090)\end{array}$ & $\begin{array}{r}-0.0362^{*} \\
(0.0191)\end{array}$ \\
\hline \multicolumn{5}{|c|}{$\frac{\text { Interaction terms: }}{\text { mother education }} \times$ liberal professional } \\
\hline$\overline{\alpha_{L .1}}$ & $\begin{array}{l}0.0342^{*} \\
(0.0204)\end{array}$ & $\begin{array}{l}-0.0088 \\
(0.0311)\end{array}$ & $\begin{array}{l}0.0522^{*} \\
(0.0267)\end{array}$ & $\begin{array}{l}-0.0610 \\
(0.0410)\end{array}$ \\
\hline$\alpha_{L .2}$ & $\begin{array}{c}-0.0267^{* * *} \\
(0.0082)\end{array}$ & $\begin{array}{c}-0.0633^{* * *} \\
(0.0141)\end{array}$ & $\begin{array}{l}-0.0111 \\
(0.0097)\end{array}$ & $\begin{array}{c}-0.0522^{* * *} \\
(0.0171)\end{array}$ \\
\hline$\alpha_{L .3}$ & $\begin{array}{l}-0.0172^{*} \\
(0.0098)\end{array}$ & $\begin{array}{c}-0.0486^{* * *} \\
(0.0176)\end{array}$ & $\begin{array}{l}-0.0061 \\
(0.0110)\end{array}$ & $\begin{array}{c}-0.0425^{* *} \\
(0.0208)\end{array}$ \\
\hline$\alpha_{L .4}$ & $\begin{array}{c}0.0121 \\
(0.0173)\end{array}$ & $\begin{array}{l}-0.0256 \\
(0.0312)\end{array}$ & $\begin{array}{c}0.0132 \\
(0.0191)\end{array}$ & $\begin{array}{l}-0.0388 \\
(0.0366)\end{array}$ \\
\hline
\end{tabular}

Notes: Source: Almalaurea XIX Profilo dei Laureati survey (2017 cohort of graduates). Sample: 159,610 students who graduated from high school and from university in Italy, from 3-years and 5-years degree cycles with non-missing value of all covariates included in the analysis. The table reports OLS estimates of linear regressions models that also include following covariates: a dummy for the region of residence in the south, a set of dummies denoting the social class that distinguish between upper class, middle class and lowerclass (the reference category), a set of dummies denoting fathers' and mothers' professions that distinguish between self-employed workers, entrepreneurs, liberal professionals, managers, teachers, white collars, stay-at-home and blue collars (the reference category). Column (1) uses data for all students. Column (2) and (3) use data on male and female students only, respectively. Estimates of column (4) correspond to interaction terms of a fully interacted model specification by student gender. Robust standard errors in parentheses. * significant at $10 \%$; ** significant at $5 \%$, ***significant at $1 \%$ or better. 
Figure 4: Average partial effects of parents field of study by liberal profession, by field of the child.

\section{Child field: Scientific studies}
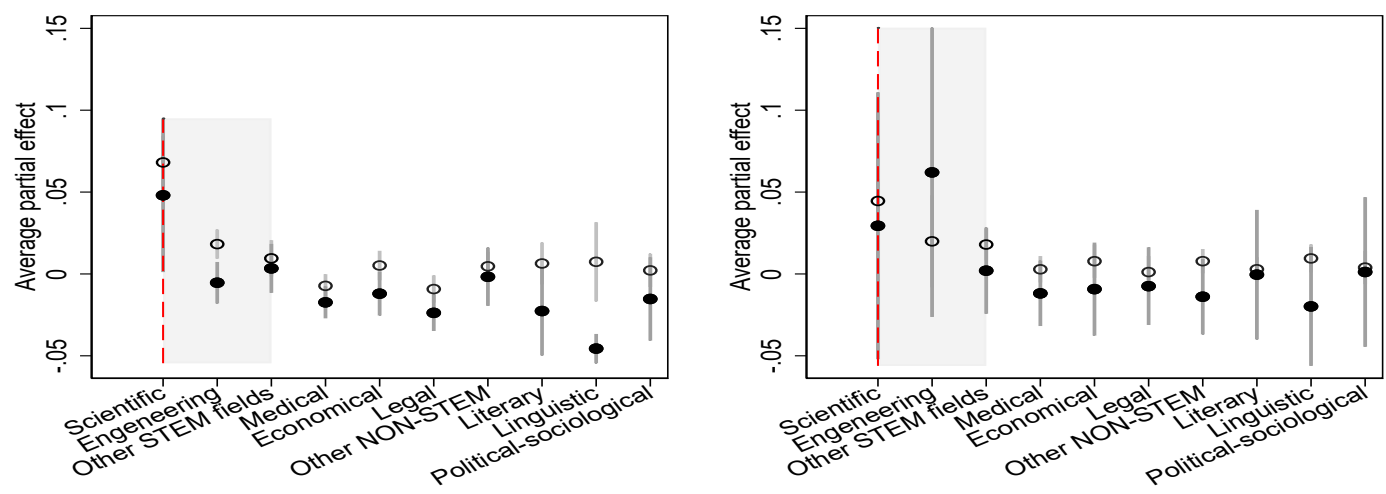

Child field: Engeneering
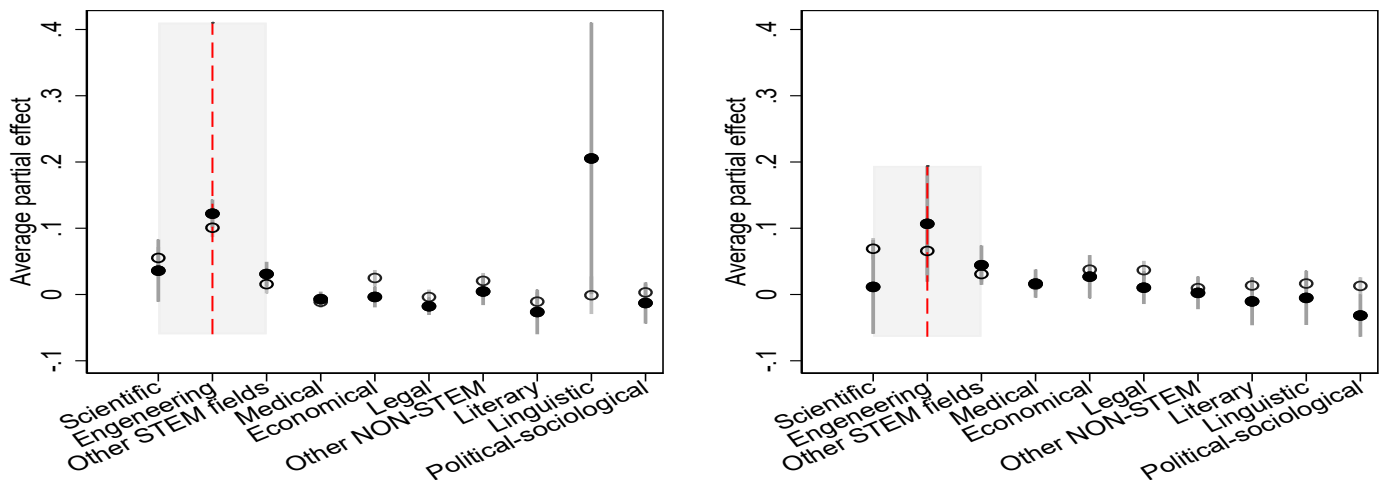

Child field: other STEM field
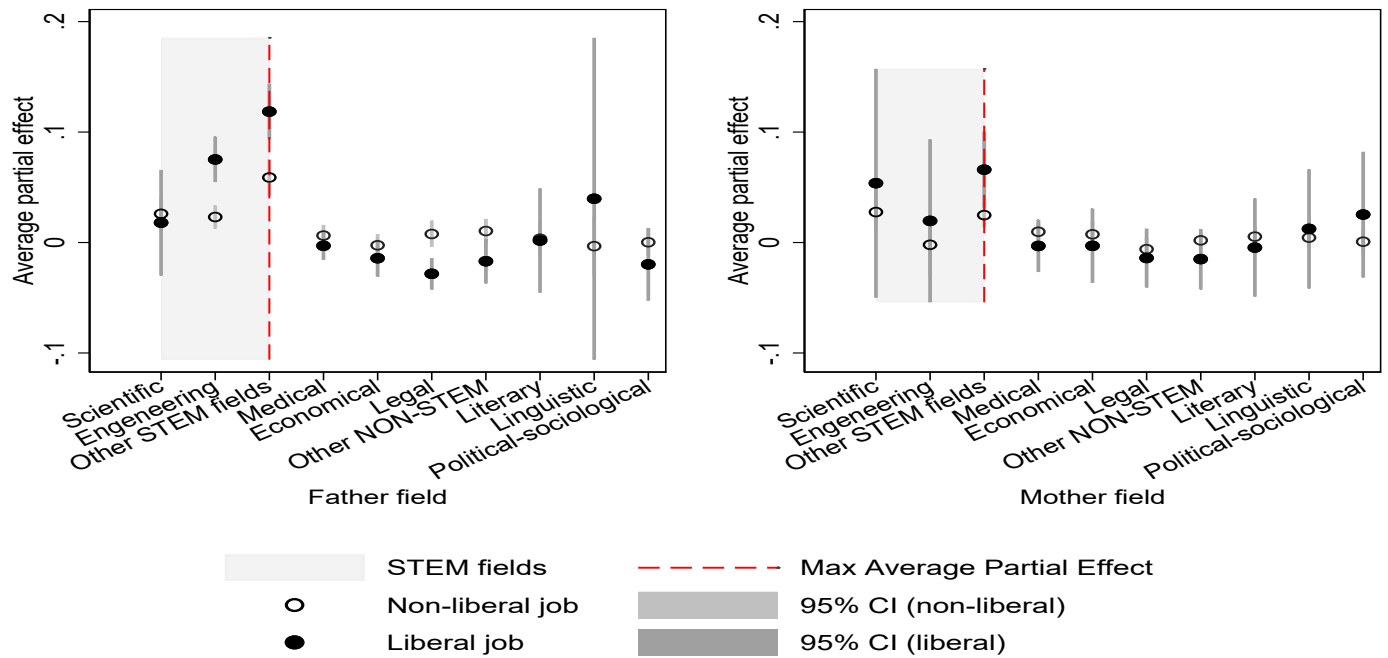

Notes: Source: Almalaurea XIX Profilo dei Laureati survey (2017 cohort of graduates). Sample: 159,610 students who graduated from high school and from university in Italy, from 3-years and 5-years degree cycles with non-missing value of all covariates included in the analysis. Each panel report estimate average partial effects obtained from parameter estimates of a multinomial logit models considering the actual field of graduation of the student among 10 mutually exclusive fields (scientific studies, engeneering, other STEM fields, medical studies, economical studies, legal studies, literary, linguistic studies, political-sociological studies, other non-STEM fields) as function of mother and father educational qualifications and field of graduation (for graduate parents). The model specification also include following covariates: a dummy for the region of residence in the south, a set of dummies denoting the social class that distinguish between upper class, middle class and lowerclass (the reference category), a set of dummies denoting fathers' and mothers' professions that distinguish between self-employed workers, entrepreneurs, liberal professionals, managers, teachers, white collars, stay-at-home and blue collars (the reference category), dummies for parents' qualification lower than university. 
Figure 5: Average partial effects of parents field of study, by field of the child Child field: Medical studies
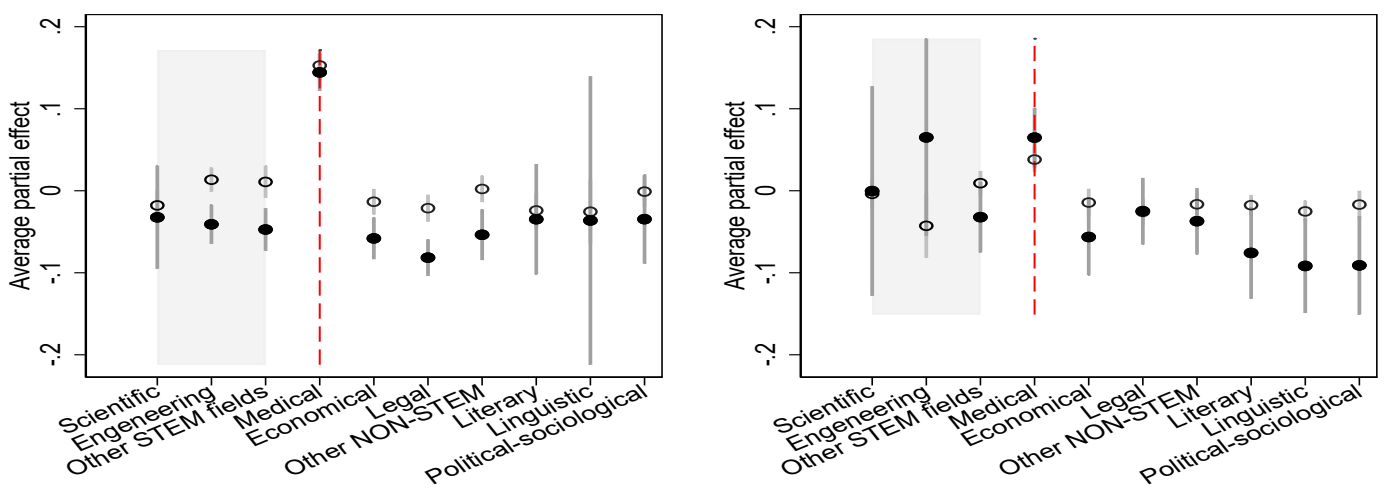

Child field: Economical studies
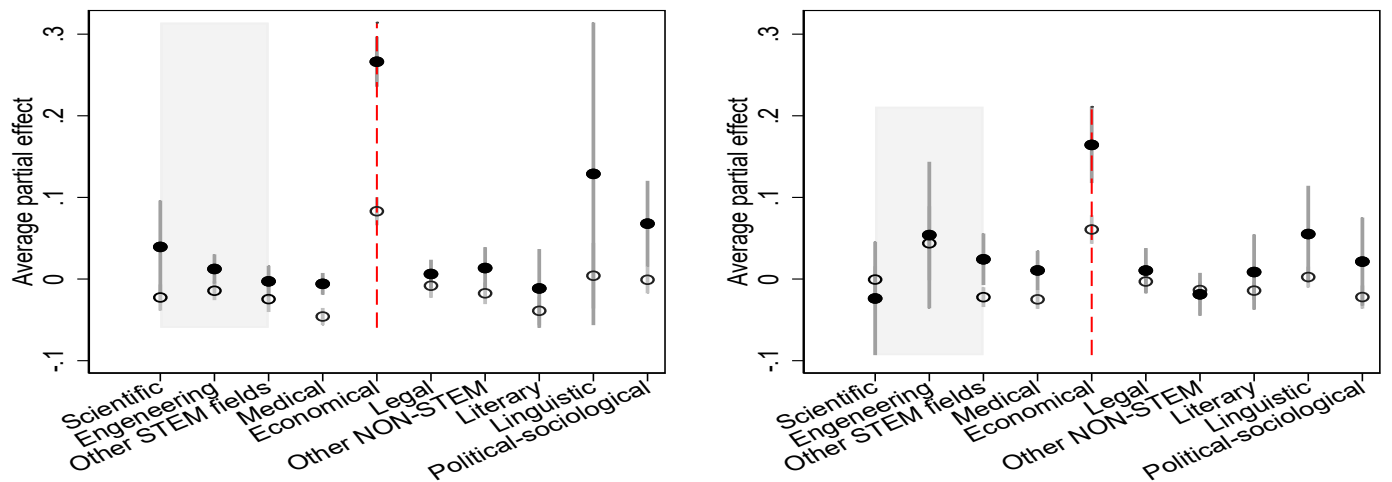

Child field: Legal Studies
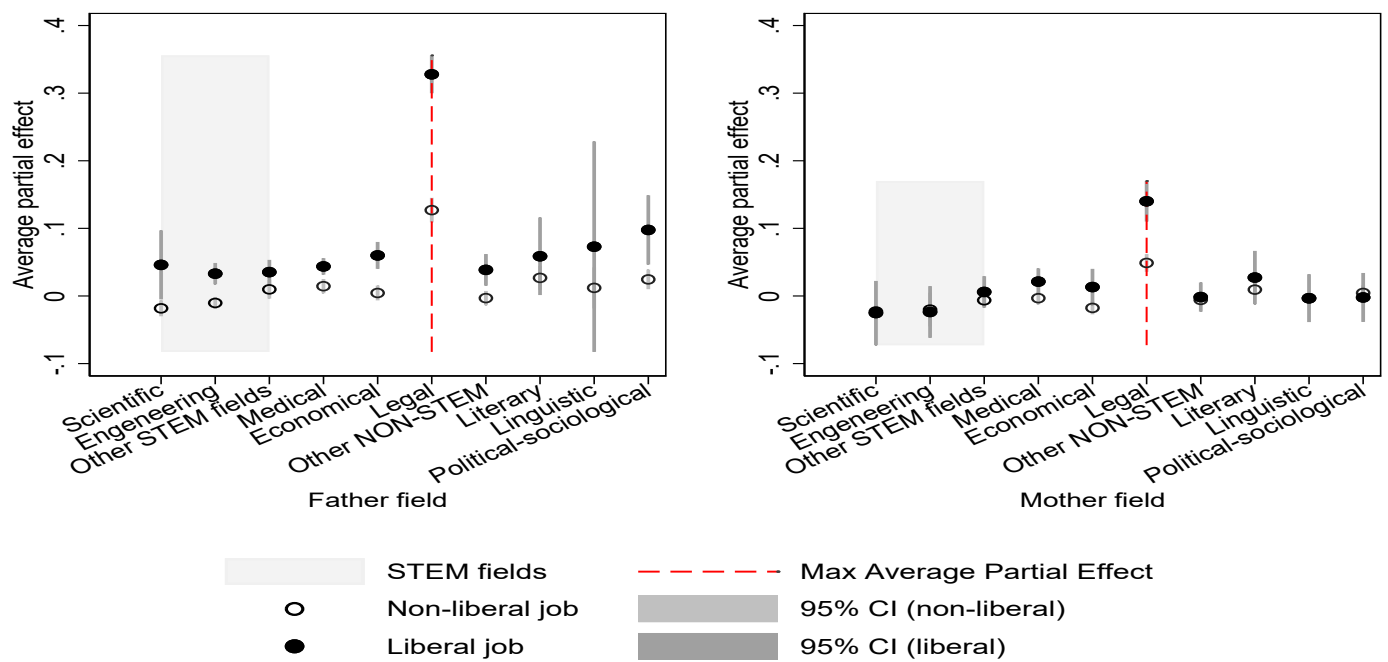

Notes: Source: Almalaurea XIX Profilo dei Laureati survey (2017 cohort of graduates). Sample: 159,610 students who graduated from high school and from university in Italy, from 3-years and 5-years degree cycles with non-missing value of all covariates included in the analysis. Each panel report estimate average partial effects obtained from parameter estimates of a multinomial logit models considering the actual field of graduation of the student among 10 mutually exclusive fields (scientific studies, engeneering, other STEM fields, medical studies, economical studies, legal studies, literary, linguistic studies, political-sociological studies, other non-STEM fields) as function of mother and father educational qualifications and field of graduation (for graduate parents). The model specification also include following covariates: a dummy for the region of residence in the south, a set of dummies denoting the social class that distinguish between upper class, middle class and lowerclass (the reference category), a set of dummies denoting fathers' and mothers' professions that distinguish between self-employed workers, entrepreneurs, liberal professionals, managers, teachers, white collars, stay-at-home and blue collars (the reference category), dummies for parents' qualification lower than university. 
Figure 6: Average partial effects of parents field of study, by field of the child Child field: other non-STEM fields
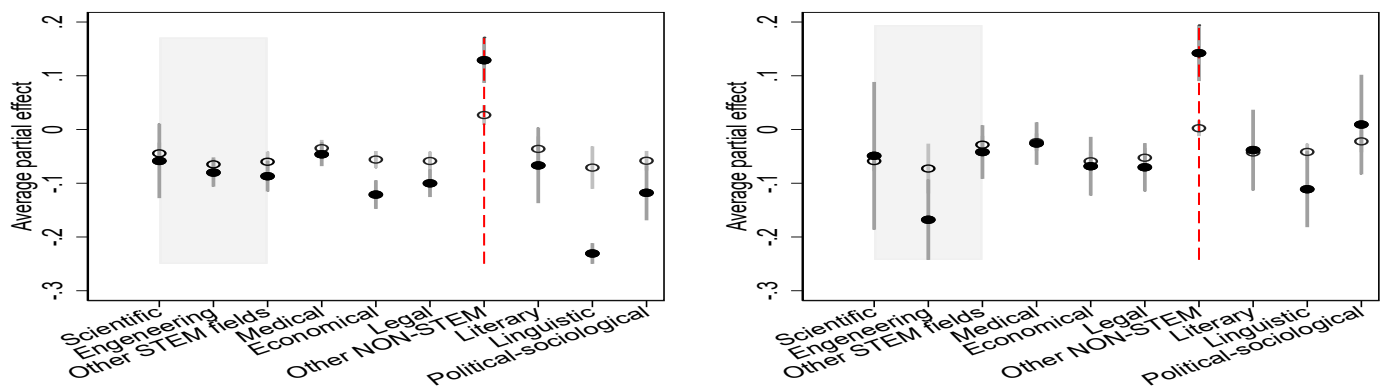

\section{Child field: Literary}
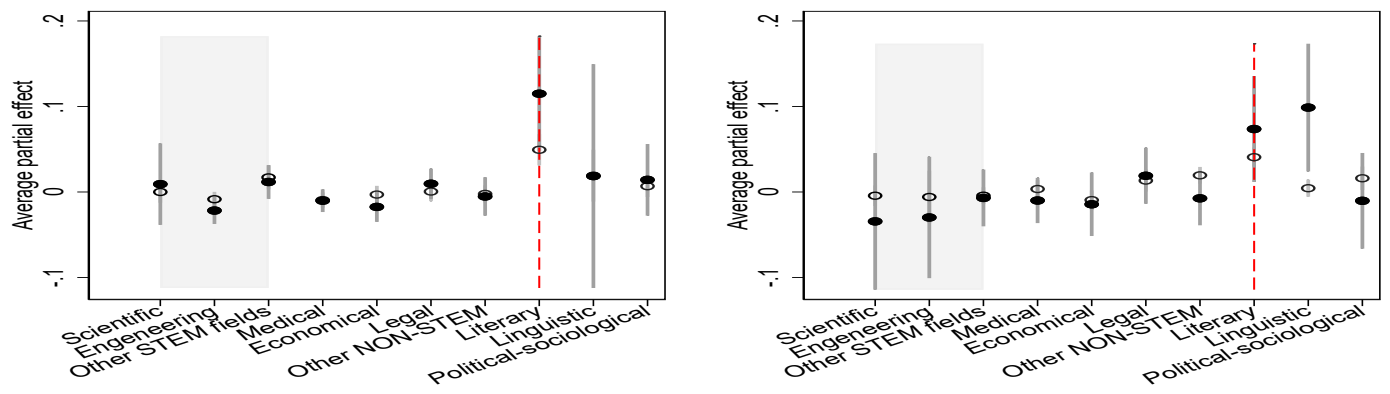

Child field: Linguistic studies
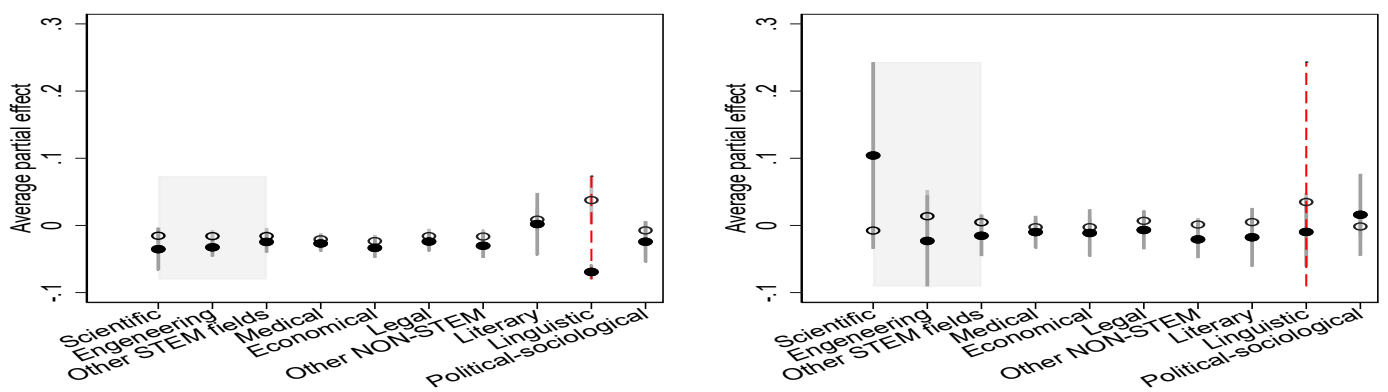

Child field: Political-sociological studies
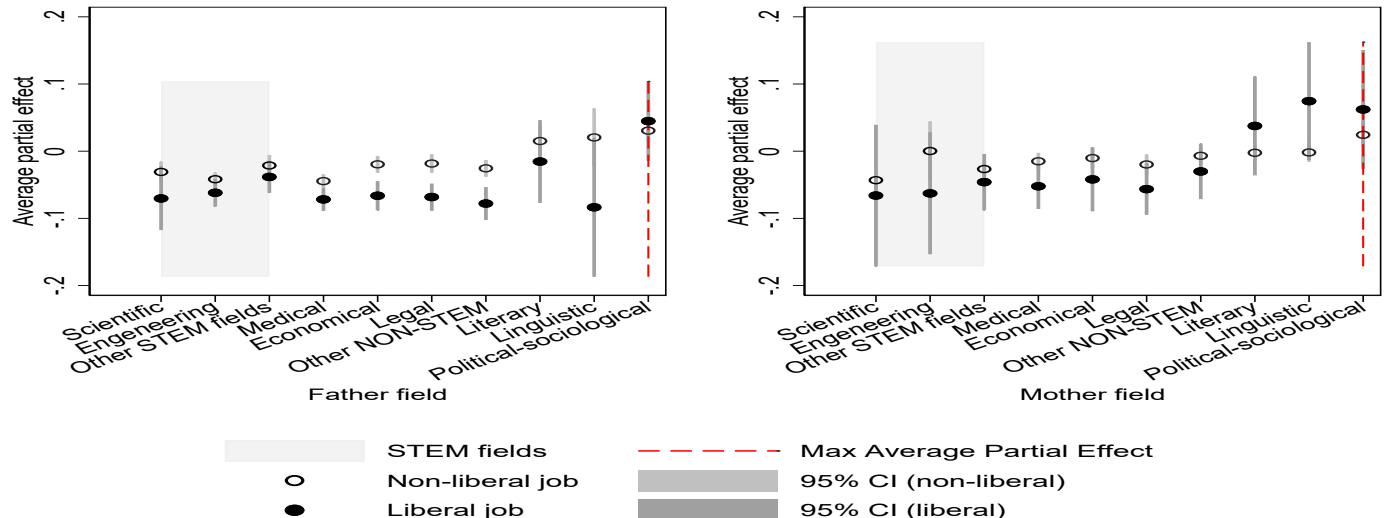

Notes: Source: Almalaurea XIX Profilo dei Laureati survey (2017 cohort of graduates). Sample: 159,610 students who graduated from high school and from university in Italy, from 3-years and 5-years degree cycles with non-missing value of all covariates included in the analysis. Each panel report estimate average partial effects obtained from parameter estimates of a multinomial logit models considering the actual field of graduation of the student among 10 mutually exclusive fields (scientific studies, engeneering, other STEM fields, medical studies, economical studies, legal studies, literary, linguistic studies, political-sociological studies, other non-STEM fields) as function of mother and father educational qualifications and field of graduation (for graduate parents). The model specification also include following covariates: a dummy for the region of residence in the south, a set of dummies denoting the social class that distinguish between upper class, middle class and lowerclass (the reference category), a set of dummies denoting fathers' and mothers' professions that distinguish between self-employed workers, entrepreneurs, liberal professionals, managers, teachers, white collars, stay-at-home and blue collars (the reference category), dummies for parents' qualification lower than university. 


\section{A Appendix - Classification of fields of study}

In this paper, we define STEM disciplines using the definition provided by the EU Comission in 2015, based on Eurostat's Classification of Fields of Education and Training (1999). This classification from Eurostat relies in turn on the International Standard Classification of Education (ISCED 1997) developed by Unesco. ISCED has been revised several times, with the latest revision in 2013 focusing exclusively on fields of education and training (ISCED-F), and it was adopted for EU data collections starting from 2016. In order to adhere to this up-to-date classification, we modified the grouping of the STEM macro categories provided by the EU 2015 report. The equivalent STEM fields of study can be classified in the following 3 categories: (i) Natural sciences, mathematics and statistics; (ii) Information and Communication Technologies; (iii) Engineering, manufacturing and construction. ${ }^{2}$ Differently from EU, we have chosen to include also Architecture since in Italy it is usually part of the department of Engineering and has many similarities with civil engineering studies. ${ }^{3}$ Instead, consistently with EU's decision, we exclude Health studies even though some studies include them, but checked that our results are robust to including them among STEM disciplines (see Section 5). This decision was taken based on considerations on the historical evolution of the perception of different jobs as well as on the presence of women. While Science has historically been viewed as non communicative, research focused and highly technical occupation, Medicine has been associated with personal care involving direct human contact and with overall equal distribution of men and women. ${ }^{4}$

The Italian university system is organised in three cycles, according to the Bologna framework adopted in 1999: the main academic degrees are the Laurea (1st cycle) which corresponds to Bachelor degree, the Laurea Magistrale (2nd cycle) which is equivalent to Master degree, and the Dottorato di Ricerca (3rd cycle) - PhD. In our study we include students having achieved both 1st and 2nd cycle degrees. These are further structured into "classes", according to the general educational objectives they share and core learning activities they must include. The Italian Ministry of Education (MIUR) has updated the correspondence between the Italian "classes" and the ISCED-F 2013 classification in 2016. This enabled us to give a very precise and up-to-date definition of which courses can be labeled as STEM according to the EC guidelines, as we illustrate in section A.1 below.

\footnotetext{
${ }^{2}$ The original fields as indicated by the European Commission can be found in a report available on line at https://publications.europa.eu/en/publication-detail/-/publication/60500ed6-cbd5-11e5a4b5-01aa75ed71a1/language-en

${ }^{3}$ Most of the alternative STEM definitions include Architecture and so does EU Skills Panorama 2014 (2015) in its analytical highlight on STEM skills.

${ }^{4}$ We thank E. Luppi for the useful comments and suggestions.
} 


\section{A.1 Classification of students' fields of study}

Almalaurea provides a classification for students' degrees into broad fields of study. Overall, there are sixteen broad fields of study: scientific, chemical-pharmaceutical, geo-biological, medical, engineering, architecture, agrarian-veterinarian, economical-statistical, politicalsociological, legal, literary, linguistics, teaching, psychological, physical education, defence and security. For our analysis, the differentiation between STEM and non-STEM fields is crucial. While some of the Almalaurea groups can be entirely classified as either STEM or non-STEM, most of them contain both STEM and non-STEM degrees. Departing from the Almalaurea classification, we use the definition of STEM ISCED fields and the mapping between these fields and the Italian degrees provided by MIUR mentioned above (which can be found in the Online Appendix). This way, we have reshuffled the composition of the sixteen groups and re-assigned some of the degrees so as to create groups that contain only either STEM or non-STEM degrees. Restrictions related to sample size forced us to further aggregate some of the sixteen newly created groups and we end up with ten groups, out of which three are STEM and seven are non-STEM, as displayed in Table A-11. The detailed list of the degrees that form each of our newly created fields of study is illustrated in Table A-12 (STEM fields) and Table A-13 (non-STEM fields), together with the their original Almalaurea classification. ${ }^{5}$

\section{A.2 Classification of parents' fields of study}

Parents' degree in our dataset is declared by students in the form of free text. These data have not undergone any classification by Almalaurea. Our goal hence was to clean and classify parents' degrees in a comparable way to the classification of students' degrees. However, given that the parents obtained their degrees before the Bologna process and hold the so called "vecchio ordinamento" degrees $^{6}$ we cannot classify them according to the new "classes" introduced in 1999. The best we can do is to classify parents' degrees into the same broad fields of studies used for the students. We recur to text mining techniques to clean the data and assign each degree to a specific group based on the words characterizing the field. Following the same logic as described for students' classification in Appendix A.1, we proceed

\footnotetext{
${ }^{5}$ Consistently with our sample selection, only 3-years cycle degrees (i.e. "Laurea") and 5-years cycle degrees (i.e. "Laurea magistrale a ciclo unico") are displayed in the list.

${ }^{6}$ Before the Bologna process all the study cycle lasted 4 years while after it was separated into $3+2$ of Bachelor plus Master. We do not know the date in which parents graduate but given the years in which the Bologna process started (1999) is it highly implausible that parents graduated under the new system.
} 
with a three-steps approach: we first assign the degree to one of the sixteen fields of study as defined by Almalaurea, afterwards we reshuffle the structure of some of these sixteen groups to contain only STEM or non-STEM degrees and finally we aggregate some groups to end up with ten final groups for the father (Table A-14) and for the mother (Table A-15). All three sets of groups of the parents contain the same degree types as the children. E.g., in the first step we classify in the Almalaurea-equivalent group "Scientific" the degrees that contain words such has "science" (as a stand-alone word), "physics", "informatics", "mathematics", "navigation" and their composites, in the second step we customize the "Scientific" group by adding to it other STEM degrees that belong to non-STEM Almalaurea groups such as "chemistry", "pharmaceutics" and "statistics". The group "Scientific" does not undergo the third step since it remains a stand-alone also in our final classification. In total,we classified 32,803 observations for fathers' degrees and 30,930 for mothers' degrees.

\section{A.3 Classification of field of study at high school}

As mentioned in the paper, we consider -beside the university field of study- the field of the high school degree previously achieved by the student. This required a further classification into STEM/non-STEM of the secondary education diplomas obtained by the students and opening access to university. We categorized as STEM scientific high schools and selected technical high schools based on high mathematical/technical content of the curriculum of studies.

STEM high schools include: scientific high school (liceo scientifico) and technical institutes (istituti tecnici) with following specialisations: industrial (istituto tecnico industriale), surveying (istituto tecnico per geometri), nautical (istituto tecnico nautico), aeronautical (istituto tecnico aeronautico).

All the remaining high schools were categorized as non-STEM. Non-STEM high schools include: classical high school (liceo classico), psycho-socio-pedagogical high school (liceo psico-socio-pedagogico) or teacher training school (istituto magistrale), linguistic high school (liceo linguistico), fine arts high school (liceo artistico), artistic school (istituto d'arte), technical institutes with specialisation in commerce (istituto tecnico commerciale), agriculture (istituto tecnico agrario), business administration (istituto tecnico per periti aziendali), social service (istituto tecnico femminile per $i$ servizi sociali), and vocational schools (istituti professionali). 
Table A-11: Distribution of students by field of study

\begin{tabular}{lcc}
\hline Field & Frequency & Percentage \\
\hline STEM fields & & \\
Scientific & 7,704 & 4.83 \\
Engineering & 15,991 & 10.02 \\
OtherSTEM & 12,697 & 7.96 \\
Non-STEM fields & & \\
Medical & 24,299 & 15.22 \\
Economical & 19,585 & 12.27 \\
Political-sociological & 15,123 & 9.47 \\
Legal & 13,173 & 8.25 \\
Literary & 12,132 & 7.60 \\
Linguistic & 11,391 & 7.14 \\
OtherNon-STEM & 27,515 & 17.24 \\
\hline Observations & 159,610 & 100.00 \\
\hline & &
\end{tabular}

Notes: Other STEM fields includes Geo-biological and Architecture. Other non-STEM fields includes Pharmaceutical, Agrarianveterinarian, Teaching, Psychological, Physical education, Defence and security. 
Table A-12: List of STEM degrees by fields of study of the students

\section{STEM fields}

\section{Scientific (Scientifico)}

Scienze e tecnologie chimiche (21)

Scienze e tecnologie della navigazione marittima e aerea (22)

Scienze e tecnologie farmaceutiche (24)

Scienze e tecnologie fisiche (25)

Scienze e tecnologie informatiche (26)

Scienze matematiche (32)

Scienze statistiche (37)

Scienze e tecnologie chimiche (L-27)

Scienze e tecnologie della navigazione (L-28)

Scienze e tecnologie farmaceutiche (L-29)

Scienze e tecnologie fisiche (L-30)

Scienze e tecnologie informatiche (L-31)

Scienze matematiche (L-35)

Statistica (L-41)

\section{Engineering (Ingengeria)}

Ingegneria civile e ambientale (8)

Ingegneria dell'informazione (9)

Ingegneria industriale (10)

Ingegneria civile e ambientale (L-7)

Ingegneria dell'informazione (L-8)

Ingegneria industriale (L-9)

\section{Almalaurea group}

Chemical-pharmaceutical

Scientific

Chemical-pharmaceutical

Scientific

Scientific

Scientific

Economical-statistical

Chemical-pharmaceutical

Scientific

Chemical-pharmaceutical

Scientific

Scientific

Scientific

Economical-statistical

\section{Other STEM fields (Altri corsi STEM)}

\section{Geo-biological (Geo-biologico)}

Biotecnologie (1)

Scienze biologiche (12)

Scienze della Terra (16)

Scienze e tecnologie per l'ambiente e la natura (27)

Biotecnologie (L-2)

Scienze biologiche (L-13)

Scienze e tecnologie per l'ambiente e la natura (L-32)
Engineering

Engineering

Engineering

Engineering

Engineering

Engineering
Geo-biological

Geo-biological

Geo-biological

Geo-biological

Geo-biological

Geo-biological

Geo-biological 
Table A-12: List of STEM degrees by fields of study of the students

\section{STEM fields}

Scienze geologiche (L-34)

\section{Almalaurea group}

Geo-biological

Architecture

Scienze dell'architettura e dell'ingegneria edile (4)

Urbanistica e scienze della pianificazione territoriale e ambi- Architecture entale (7)

Tecnologie per la conservazione e il restauro dei beni culturali Literary

Architettura e ingegneria edile (4/S)

Architecture

Scienze dell'architettura (L-17)

Architecture

Scienze della pianificazione territoriale, urbanistica, paesaggis- Architecture tica e ambientale (L-21)

Scienze e tecniche dell'edilizia (L-23)

Architecture

Diagnostica per la conservazione dei beni culturali - EX tecn. Literary

per la conservaz. e il restauro dei beni cult. (L-43)

Architettura e ingegneria edile-architettura (LM-4 C.U.)

Architecture

Conservazione e restauro dei beni culturali - Ciclo Unico Literary

(LMR/02) 
Table A-13: List of STEM degrees by fields of study of the students

\begin{tabular}{ll}
\hline Non-STEM fields & Almalaurea group \\
\hline Medical (Medico) & \\
Professioni sanitarie infermieristiche e professione sanitaria os- & Medical \\
tetrica (SNT/1) & \\
Professioni sanitarie della riabilitazione (SNT/2) & Medical \\
Professioni sanitarie tecniche (SNT/3) & Medical \\
Professioni sanitarie della prevenzione (SNT/4) & Medical \\
Professioni sanitarie, infermieristiche e professione sanitaria & Medical \\
Ostetrica (L/SNT1) & \\
Professioni sanitarie della riabilitazione (L/SNT2) & Medical \\
Professioni sanitarie tecniche (L/SNT3) & Medical \\
Professioni sanitarie della prevenzione (L/SNT4) & Medical \\
\hline
\end{tabular}

\section{Economical (Economico)}

Scienze dell'economia e della gestione aziendale (17)

Economical-statistical

Scienze economiche (28)

Economical-statistical

Scienze dell'economia e della gestione aziendale (L-18)

Economical-statistical

Scienze economiche (L-33)

Economical-statistical

\section{Legal (Giuridico)}

Scienze dei servizi giuridici (2)

Legal

Scienze giuridiche (31)

Legal

Giurisprudenza (22/S)

Legal

Scienze dei servizi giuridici (L-14)

Legal

Giurisprudenza (LMG/01)

Legal

\section{Other non-STEM fields (Altri corsi non-STEM)}

\section{Pharmaceutical (Farmaceutico)}

Farmacia e farmacia industriale (14/S)

Farmacia e farmacia industriale (LM-13)

\section{Agrarian-veterinarian (Agrario-vetrinario)}

Scienze e tecnologie agrarie, agroalimentari e forestali (20)

Scienze e tecnologie zootecniche e delle produzioni animali (40)

Medicina veterinaria (47/S)

Scienze e tecnologie agrarie e forestali (L-25)
Chemical-pharmaceutical

Chemical-pharmaceutical

Agrarian-Veterinarian

Agrarian-Veterinarian

Agrarian-Veterinarian

Agrarian-Veterinarian 
Table A-13: List of STEM degrees by fields of study of the students

\begin{tabular}{ll}
\hline Non-STEM fields & Almalaurea group \\
\hline Scienze e tecnologie alimentari (L-26) & Agrarian-Veterinarian \\
Scienze zootecniche e tecnologie delle produzioni animali (L- & Agrarian-Veterinarian \\
$38)$ & \\
Medicina veterinaria (LM-42) & Agrarian-Veterinarian \\
Teaching (Insegnamento) & \\
Scienze dell'educazione e della formazione (18) & Teaching \\
Scienze dell'educazione e della formazione (L-19) & Teaching \\
Scienze della formazione primaria (LM-85bis) & Teaching \\
$\boldsymbol{P s y c h o l o g i c a l ~ ( P s i c o l o g i c o )}$ & \\
Scienze e tecniche psicologiche (34) & Psychological \\
Scienze e tecniche psicologiche (L-24) & Psychological \\
$\boldsymbol{P h y s i c a l}$ education (Educazione fisica) & \\
Scienze delle attività motorie e sportive (33) & Physical education \\
Scienze delle attività motorie e sportive (L-22) & Physical education \\
Defence $\boldsymbol{a n d}$ security (Difesa $\boldsymbol{e}$ sicurezza) & \\
Scienze della difesa e della sicurezza (DS/1) & Defence and security \\
\hline
\end{tabular}

\section{Literary (Letterario)}

Lettere (5)

Scienze dei beni culturali (13)

Scienze e tecnologie delle arti figurative, della musica, dello spettacolo e della moda (23)

Filosofia (29)

Scienze geografiche (30)

Scienze storiche (38)

Disegno industriale (42)

Beni culturali (L-1)

Discipline delle arti figurative, della musica, dello spettacolo e della moda (L-3)

Disegno industriale (L-4)

Filosofia (L-5)

Geografia (L-6)
Literary

Literary

Literary

Literary

Literary

Literary

Architecture

Literary

Literary

Architecture

Literary

Literary 
Table A-13: List of STEM degrees by fields of study of the students

\begin{tabular}{ll}
\hline Non-STEM fields & Almalaurea group \\
\hline Lettere (L-10) & Literary \\
Storia (L-42) & Literary \\
\hline Linguistic (Linguistico) & \\
Scienze della mediazione linguistica (3) & Linguistics \\
Lingue e culture moderne (11) & Linguistics \\
Lingue e culture moderne (L-11) & Linguistics \\
Mediazione linguistica (L-12) & Linguistics \\
\hline Political-sociological (Politico-sociale) & \\
Scienze del servizio sociale (6) & Political-sociological \\
Scienze della comunicazione (14) & Political-sociological \\
Scienze politiche e delle relazioni internazionali (15) & Political-sociological \\
Scienze dell'amministrazione (19) & Political-sociological \\
Scienze sociali per la cooperazione, lo sviluppo e la pace (35) & Political-sociological \\
Scienze sociologiche (36) & Political-sociological \\
Scienze del turismo (39) & Political-sociological \\
Scienze del turismo (L-15) & Political-sociological \\
Scienze dell'amministrazione e dell'organizzazione (L-16) & Political-sociological \\
Scienze della comunicazione (L-20) & Political-sociological \\
Scienze politiche e delle relazioni internazionali (L-36) & Political-sociological \\
Scienze sociali per la cooperazione, lo sviluppo e la pace (L-37) & Political-sociological \\
Servizio sociale (L-39) & Political-sociological \\
Sociologia (L-40) & Political-sociological \\
& \\
\hline
\end{tabular}


Table A-14: Distribution of students by field of study of father with university degree

\begin{tabular}{lcc}
\hline Field & Frequency & Percentage \\
\hline STEM fields & & \\
Scientific & 1,806 & 5.51 \\
Engineering & 5,293 & 16.14 \\
OtherSTEM & 2,882 & 8.78 \\
Non-STEM fields & & \\
Medical & 8,361 & 25.49 \\
Economical & 3,754 & 11.44 \\
Political - sociological & 1,893 & 5.77 \\
Legal & 3,967 & 12.09 \\
Literary & 1,346 & 4.10 \\
Linguistic & 327 & 1.00 \\
Othernon-STEM & 5,067 & 15.43 \\
\hline Observations & 32,803 & 100.00 \\
\hline
\end{tabular}

Notes: Other STEM fields includes Geo-biological and Architecture. Other non-STEM fields includes Pharmaceutical, Agrarianveterinarian, Teaching, Psychological, Physical education, Defence and security. 
Table A-15: Distribution of students by field of study of mother with university degree

\begin{tabular}{lcc}
\hline Field & Frequency & Percentage \\
\hline STEM fields & & \\
Scientific & 1,948 & 6.30 \\
Engineering & 333 & 1.08 \\
OtherSTEM & 3,560 & 11.51 \\
Non-STEM fields & & \\
Medical & 5,225 & 16.89 \\
Economical & 2,374 & 7.68 \\
Political-sociological & 1,926 & 6.23 \\
Legal & 3,071 & 9.93 \\
Literary & 4,270 & 13.81 \\
Linguistic & 3,398 & 10.99 \\
Othernon-STEM & 6,751 & 21.84 \\
\hline Observations & 30,930 & 100.00 \\
\hline
\end{tabular}

Notes: Other STEM fields includes Geo-biological and Architecture. Other non-STEM fields includes Pharmaceutical, Agrarianveterinarian, Teaching, Psychological, Physical education, Defence and security. 


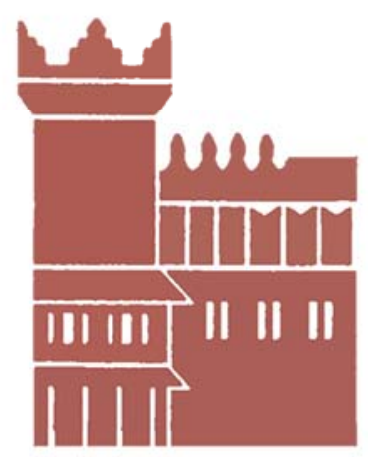

Alma Mater Studiorum - Università di Bologna DEPARTMENT OF ECONOMICS

Strada Maggiore 45

40125 Bologna - Italy

Tel. +39051 2092604

Fax +390512092664

http://www.dse.unibo.it 